\title{
Oxygen-independent chemogenetic protein tags for live-cell fluorescence microscopy
}

Aditya Iyer $\S^{\S^{*}}$, Maxim Baranov${ }^{*}$, Alexander J Foster ${ }^{\S}$, Shreyans Chordia", Gerard Roelfes", Geert van den Bogaart ${ }^{*}$, Bert Poolman $\S^{\S^{*}}$

§Department of Biochemistry, Groningen Biomolecular Sciences and Biotechnology Institute, University of Groningen, Nijenborgh 7, 9747 AG Groningen, The Netherlands

₹Department of Molecular Immunology, Groningen Biomolecular Sciences and Biotechnology Institute, University of Groningen, Nijenborgh 7, 9747 AG Groningen, the Netherlands

"Stratingh Institute for Chemistry, University of Groningen, Nijenborgh 4, 9747 AG Groningen, The Netherlands

*Email for correspondence: a.s.iyer@rug.nl; b.poolman@rug.nl

Keywords: Fluorescence microscopy, chemogenetic fluorogenic probes, live-cell imaging, fluorescence lifetime imaging, anaerobic microorganisms, eukaryotic cells, self-labeling protein tags 


\section{ABSTRACT}

2 Fluorescent proteins enable targeted visualization of biomolecules in living cells, but their

3 maturation is oxygen-dependent and they are susceptible to aggregation and/or suffer from poor photophysical properties. Organic fluorophores are oxygen-independent with superior photophysical properties, but targeting biomolecules in vivo is challenging. Here, we introduce two oxygen-independent chemogenetic protein (OICP) tags that impart

7 fluorogenicity and fluorescence lifetime enhancement to bound organic dyes. We present a 8 photo- and physicochemical characterization of thirty fluorophores interacting with two 9 OICPs and conclude that aromatic planar structures bind with high specificity to the 10 hydrophobic pockets of the proteins. The binding specificity of the tags and the superior 11 photophysical properties of organic fluorophores enable microscopy of living bacterial and 12 eukaryotic cells. The exchange of photobleached dye for unbleached fluorophore enables 13 prolonged live-cell imaging. Our protein tags provide a general tool for investigating 14 (sub)cellular protein localization and dynamics, protein-protein interactions, and microscopy 15 applications under strictly oxygen-free conditions.

\section{INTRODUCTION}

18 Biochemistry is evolving from mostly in vitro studies of macromolecules to in vivo analyses

19 of complex processes in living cells, wherein macromolecules and multiprotein complexes 20 are mapped three-dimensionally with high spatial and temporal resolution and full 21 functionality. To attain this, fluorescence live-cell imaging techniques have traditionally 22 relied on tagging specific proteins in their native cellular environment with genetically 23 encoded fluorescent proteins (FPs)(Rodriguez et al., 2016; Shaner et al., 2005). FPs are 24 target-specific but often fall short in photophysical characteristics when benchmarked 25 against organic fluorophores. Additionally, the anaerobic conditions of the gut and other environments pose a significant barrier for FP-based fluorescence imaging for investigating 27 the physiology of endogenous microorganisms(Tropini et al., 2017). This is because FPs 28 require molecular oxygen for chromophore maturation(Tsien, 1998) with the exception of

29 flavin mononucleotide-dependent fluorescent protein((Drepper et al., 2007)) and the 30 recently discovered bilirubin-dependent UnaG protein(Kumagai et al., 2013), and this 31 requirement is a major obstacle hindering the studies of anaerobic microorganisms or cellular compartments low in oxygen. 
1 Alternative to FPs, modified organic fluorophores, and/or bait proteins exist that capture a

2 specific ligand coupled to organic fluorophores. Organic fluorophores typically have better

3 photophysical characteristics compared to FPs such as greater photostability, longer

4 fluorescent lifetimes, higher quantum yields and a wider spectral range, and importantly do not require oxygen for fluorescence(Balleza et al., 2018; Cranfill et al., 2016; Grimm et al., 2016; Jing and Cornish, 2011; Kocaoglu and Carlson, 2016; Shaner et al., 2005). Organic

fluorophores are notorious for non-specific interactions with cellular components and high background signals. Not surprisingly, strategies to make smaller FPs with improved photophysical characteristics(Dippel et al., 2020; Drepper et al., 2007; Nagai et al., 2002), developing organic fluorophores with enhanced specificity and fluorogenicity (enhanced fluorescence upon binding target)(Kowada et al., 2015; Song et al., 2014), and peptide-tags like SNAP-tag ${ }^{\circledR}$ and HaloTag® have gained traction(Grimm et al., 2017; Jing and Cornish, 2011; Kocaoglu and Carlson, 2016; Wang et al., 2020). The application of these important tools can be limited by high nonspecific staining(Bosch et al., 2014) and poor cell permeability of the dyes(Keppler et al., 2004). Recently, SNAP-tag® and HaloTag® substrates have been covalently coupled to 6-TAMRA derivatives (MaP probes) that displayed enhanced cell permeability and fluorogenicity(Wang et al., 2020). However, as of now such strategies require specific chemistry for ligand binding; and employ ligands that irreversibly and/or covalently bind to the modified fluorophore. Furthermore, synthesis of such modified fluorophores is nontrivial and their availability is limited. Whereas the covalent linkage of SNAP-tag ${ }^{\circledR}$ and HaloTag ${ }^{\circledR}$ substrates is advantageous in some experimental designs, it may not be always desirable as a non-covalent reversible binding of fluorophores can be preferable for long-term imaging as fluorophores can be exchanged for non-photobleached ones.

To address the aforementioned issues and alleviate the need to synthesize or modify commercially available fluorophores, we present a straightforward labeling strategy that achieves fluorogenicity, lifetime enhancement, and target recognition of non-covalently bound dyes in a variety of organisms. We introduce a self-labeling protein tagging system that combines the best of genetic tags and organic fluorophores developed through a chemogenetic approach. Our approach exploits the unique biochemical properties of two small, bacterial transcriptional factors, namely: resistance antibiotic multiple regulator(Yamasaki et al., 2013, 2019) (RamR) and lactococcal multidrug resistance repressor(Madoori et al., 2009; Roelfes, 2019; Takeuchi et al., 2014) (LmrR) that differ in sequence, molecular weight and structure (Supplementary Fig. 1). Both RamR (from the 
1 Gram-negative bacterium Salmonella typhimurium(Yamasaki et al., 2019)) and LmrR (from

2 the Gram-positive bacterium Lactococcus lactis(Agustiandari et al., 2008)) are homo-

3 dimeric proteins that contain hydrophobic pocket(s) where planar organic compounds bind

4 non-covalently with high specificity. Under native conditions, RamR and LmrR act by

5 repressing the synthesis of multidrug efflux pumps, and this effect is removed upon binding

6 to organic compounds such as antibiotics. The hydrophobic pocket(s) are attractive

7 scaffolds since they bind a variety of aromatic molecules.

\section{RESULTS}

10 We envisioned that seclusion of planar organic fluorophores into the hydrophobic binding 11 pockets within LmrR(Mejías et al., 2020) and RamR (hereafter named oxygen-independent 12 chemogenetic protein (OICP) tags) could improve their photophysical properties, which 13 depends on the distinct chemical environment of the protein binding sites. Furthermore, we 14 used engineered variants of $\mathrm{LmrR}$ to minimize unspecific interactions of the tags with cell 15 components (see Methods section). Indeed, in vitro characterization of the spectroscopic 16 properties of 30 organic fluorophores, several have applications in super-resolution 17 microscopy and single-particle tracking, demonstrated that BODIPY, SNAP- and Halo-tag 18 conjugated dyes and rhodamine-based fluorophores show a significant and correlated 19 increase in fluorescence (up to 35-fold) with absorbance increase (up to 10-fold) in the 20 presence of OICP tags, while that of others was either quenched or not affected (Figure 21 1a-c, Table 1 and Supplementary Figs. 2-18). We verified the promiscuity of the 22 hydrophobic dye-binding pockets using organic dyes that attain fluorogenicity in

23 hydrophobic environments (Table 1: non-specific intercalators). 
a
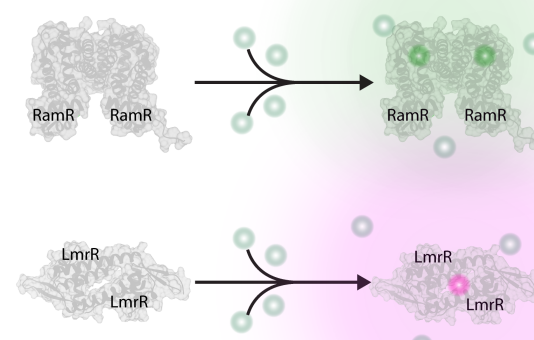

d

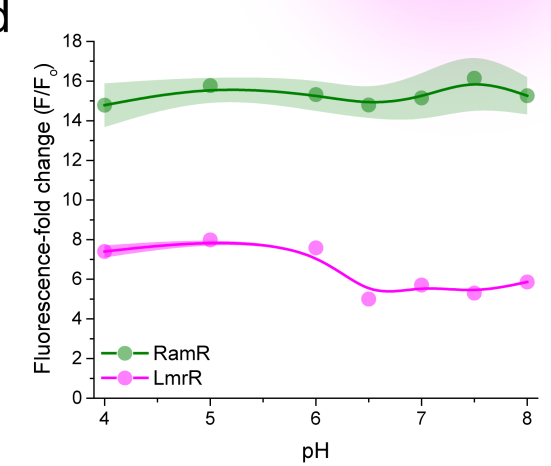

9

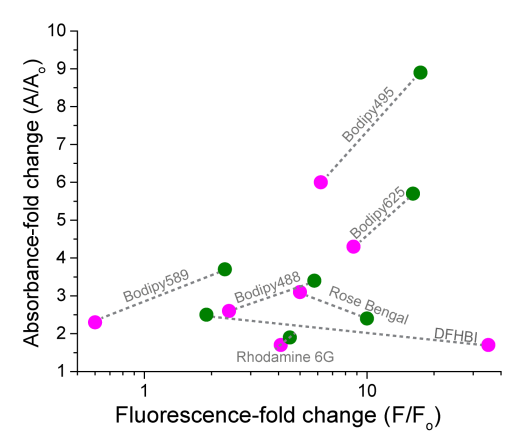

b

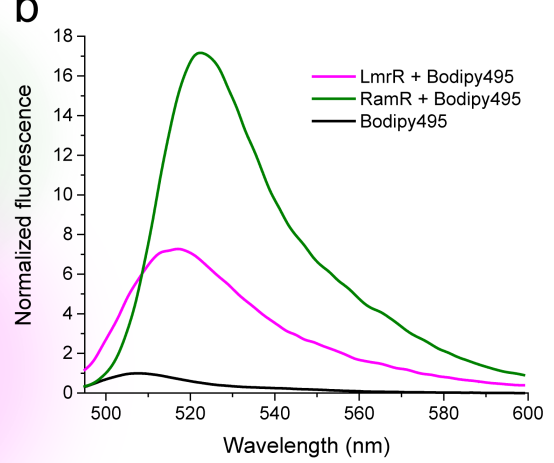

e

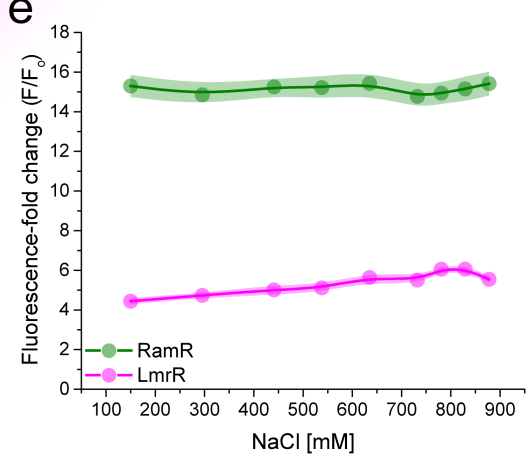

$\mathrm{h}$

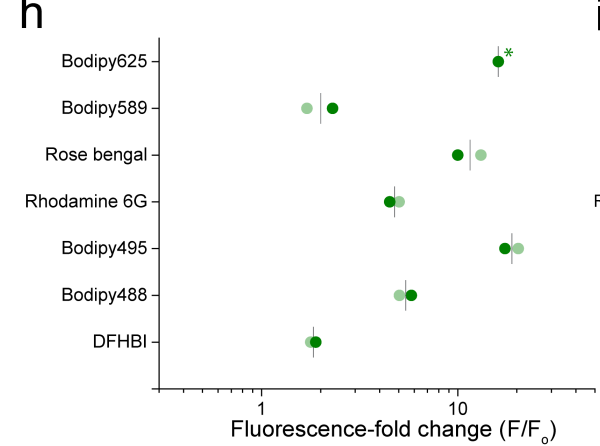

C

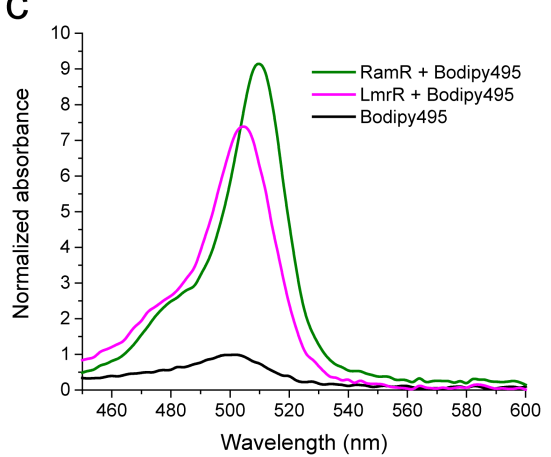

$f$

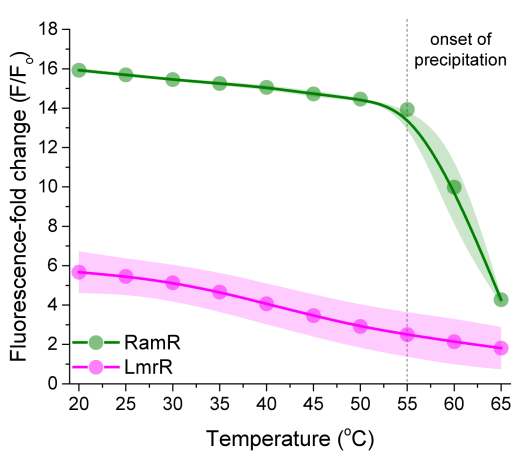

i

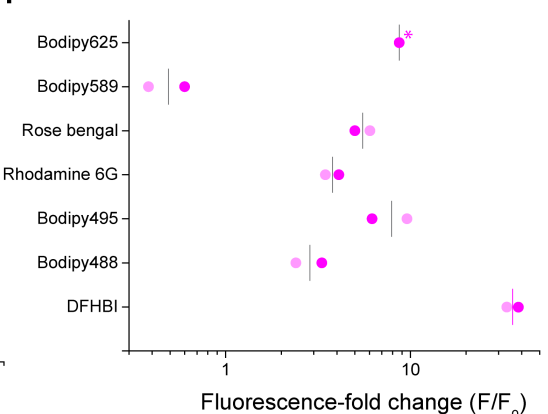

Figure 1. In vitro characterization of OICP tags. (a) Working principle of OICP tags: RamR (green) and LmrR (magenta). (b) Fluorescence emission spectra depicting fold-change in fluorescence emission intensity of Bodipy495 after adding of OICP tags. (c) Absorption spectra depicting fold-change in the absorption of Bodipy495 after the addition of OICP tags. (d-f) Fold-change in Bodipy495 fluorescence emission intensity across $\mathrm{pH}(\mathrm{d}), \mathrm{NaCl}$ concentration (e) and temperature (f). The dotted line in panel $\mathrm{f}$ indicates the onset of partial precipitation of RamR. The solid lines in panels d-f are spline fits and the color-shaded regions represent s.d. over three independent measurements. g) Correlation plots of fold-change in absorbance and fluorescence for 7 fluorogenic dyes. Grey dotted lines connect the values for the respective dye. (h-i) Effect of oxygen on the fluorogenicity of dyes in the presence of OICP tags. The fold change in fluorescence in the absence of oxygen (faded points) is comparable with that in the presence of oxygen (solid points). Foldchange in fluorescence of Bodipy625 in the absence of oxygen (indicated with asterisks) could not be measured due to the lack of the appropriate excitation source.

14 We first characterized the physicochemical robustness of the purified OICP tags in detail in 15 vitro. Using Bodipy495, the dye with the highest fluorogenicity amongst the seven

16 fluorogenic dyes, we show that both OICP tags are insensitive to $\mathrm{pH}$ in the range from 4 to

178 , salt concentrations up to $880 \mathrm{mM}$, temperatures up to $55^{\circ} \mathrm{C}$ (Figure 1d-f) and crowding 18 agent Ficoll70 (Supplementary Fig. 19), allowing applications in diverse environments.

19 The fluorogenic behavior of the seven dyes is accompanied by corresponding increases in 20 absorbance (Figure 1g, Table 1, and Supplementary Fig 26). We also show that the dyes 21 remain fluorescent in the absence and presence of oxygen (Figure $\mathbf{1 h}-\mathbf{i}$ ). 
1 Table 1. Spectral properties of tested fluorophores in the presence of OICP tags ${ }^{1}$.

\begin{tabular}{|c|c|c|c|c|c|c|c|c|c|c|c|c|c|}
\hline Dye & $\begin{array}{l}\text { Mw } \\
\text { (Da) }\end{array}$ & $\begin{array}{c}\boldsymbol{\varepsilon} \\
\left(\mathbf{M}^{-1} \mathrm{~cm}^{-1}\right)\end{array}$ & $\lambda_{\mathrm{ex}} / \lambda_{\mathrm{em}}$ & $\begin{array}{l}\mathbf{F} / \mathbf{F}_{\text {o }} \\
\text { (RamR) }\end{array}$ & $\begin{array}{l}\text { F/F。 } \\
\text { (LmrR) }\end{array}$ & $\begin{array}{l}\text { A/A } \\
\text { (RamR) }\end{array}$ & $\begin{array}{l}\mathbf{A} / \mathbf{A}_{\text {o }} \\
\text { (LmrR) }\end{array}$ & $\begin{array}{c}\mathbf{K}_{\mathrm{a}} \\
(\mathrm{RamR})\end{array}$ & $\begin{array}{c}\mathbf{K}_{\mathrm{a}} \\
(\mathrm{LmrR})\end{array}$ & $\begin{array}{l}\tau_{\text {dye }} \\
\text { (ns) }\end{array}$ & $\begin{array}{c}\tau_{\text {RamR }} \\
(\mathrm{ns})\end{array}$ & $\tau_{\text {LmrR }}$ & Note \\
\hline DFHBI & 252.2 & 24,271 & $420 / 495$ & 1.9 & 35.1 & 2.5 & 1.7 & $>10$ & $>10$ & 0.3 & 0.4 & 1.8 & \multirow{7}{*}{ Enhanced } \\
\hline Bodipy488 & 262.0 & 79,000 & $488 / 503$ & 5.8 & 2.4 & 3.4 & 2.6 & 1.2 & 3.5 & 5.6 & 6.8 & 7.1 & \\
\hline Bodipy495 & 324.0 & 45,000 & $495 / 508$ & 17.4 & 6.2 & 8.9 & 6.0 & 0.2 & 2.2 & 3.8 & 6.8 & 5.1 & \\
\hline Rhodamine 6G & 479.0 & 116,000 & $530 / 555$ & 4.5 & 4.1 & 1.9 & 1.7 & 0.4 & 0.3 & 3.8 & 4.2 & 3.8 & \\
\hline Rose Bengal & 1017.6 & 90,400 & $559 / 568$ & 10.0 & 5.0 & 2.4 & 3.1 & 0.7 & 1.7 & 0.3 & 1.5 & 1.7 & \\
\hline Bodipy589 & 424.2 & 69,000 & $589 / 622$ & 2.3 & 0.6 & 3.7 & 2.3 & 0.1 & n.d. & 4.9 & 5.9 & 5.8 & \\
\hline Bodipy625 & 450.3 & 97,000 & $628 / 642$ & 16.1 & 8.7 & 5.7 & 4.3 & 5.7 & 0.6 & 3.2 & 4.7 & 4.6 & \\
\hline Riboflavin & 376.4 & 12,544 & $450 / 540$ & 0.8 & 0.4 & n.d. & n.d. & n.d. & n.d. & 4.1 & 5.2 & 5.2 & \multirow{8}{*}{$\begin{array}{l}\text { Quenched } \\
\quad \text { or } \\
\text { Unaffected }\end{array}$} \\
\hline AlexaFluor488 & 643.4 & 73,000 & $494 / 519$ & 0.9 & 1.0 & n.d. & n.d. & n.d. & n.d. & 3.9 & 3.9 & 4.0 & \\
\hline Bodipy FL COOH & 292.1 & 80,000 & $503 / 511$ & 0.6 & 0.7 & n.d. & n.d. & n.d. & n.d. & 5.5 & 6.3 & 5.6 & \\
\hline Eosin $Y$ & 647.9 & 112,000 & $524 / 543$ & 1.5 & 0.8 & n.d. & n.d. & n.d. & n.d. & 1.1 & 2.4 & 2.7 & \\
\hline Bodipy R6G COOH & 340.1 & 70,000 & $530 / 548$ & 0.5 & 0.8 & n.d. & n.d. & n.d. & n.d. & 5.2 & 6.2 & 5.1 & \\
\hline 6-TAMRA & 430.5 & 92,000 & $543 / 575$ & 1.0 & 0.9 & n.d. & n.d. & n.d. & n.d. & 2.5 & 2.5 & 2.5 & \\
\hline Bodipy558 & 346.2 & 84,400 & $561 / 569$ & 0.6 & 0.6 & n.d. & n.d. & n.d. & n.d. & 5.2 & 5.6 & 5.0 & \\
\hline AlexaFluor647 & 1025.2 & 270,000 & $651 / 672$ & 1.1 & 0.8 & n.d. & n.d. & n.d. & n.d. & 1.1 & 1.9 & 2.6 & \\
\hline Probe 6 & 682.3 & 22,000 & $555 / 578$ & 2.5 & 1.9 & n.d. & n.d. & n.d. & n.d. & 3.5 & 3.7 & 3.8 & \multirow{8}{*}{$\begin{array}{c}\text { SNAP-/ } \\
\text { Halo- tag } \\
\text { dependent }\end{array}$} \\
\hline Probe 10 & 788.3 & 3,500 & $556 / 576$ & 4.2 & 3.8 & n.d. & n.d. & n.d. & n.d. & 2.5 & 2.7 & 2.7 & \\
\hline Probe 11 & 635.3 & 58,000 & $555 / 578$ & 3.1 & 2.2 & n.d. & n.d. & n.d. & n.d. & 2.9 & 4.1 & 3.8 & \\
\hline Probe 15 & 742.3 & 5,200 & $555 / 578$ & 1.8 & 1.3 & n.d. & n.d. & n.d. & n.d. & 2.5 & 2.8 & 2.8 & \\
\hline Probe 22 & 579.2 & 40,000 & $505 / 527$ & 2.7 & 2.5 & n.d. & n.d. & n.d. & n.d. & 4.1 & 4.1 & 4.1 & \\
\hline Probe 23 & 685.2 & 4,500 & $510 / 531$ & 4.2 & 5.1 & n.d. & n.d. & n.d. & n.d. & 3.8 & 4.2 & 4.2 & \\
\hline Probe 29 & 661.3 & 109,000 & $615 / 635$ & 2.2 & 2.0 & n.d. & n.d. & n.d. & n.d. & 3.2 & 3.6 & 3.3 & \\
\hline Probe 33 & 767.4 & 260 & $618 / 635$ & 1.1 & 1.0 & n.d. & n.d. & n.d. & n.d. & 3.1 & 3.2 & 3.3 & \\
\hline Ethidium bro & 394.3 & 5,450 & $360 / 618$ & 3.6 & 1.5 & n.d. & n.d. & n.d. & n.d. & n.d. & n.d. & n.d. & \multirow{7}{*}{$\begin{array}{l}\text { Non-specific } \\
\text { intercalators }\end{array}$} \\
\hline Hoechst 33342 & 616.0 & 47,000 & $361 / 460$ & 33.5 & 65.4 & n.d. & n.d. & n.d. & n.d. & n.d. & n.d. & n.d. & \\
\hline $\mathrm{DPH}$ & 461.6 & 88,000 & $350 / 395$ & 17.9 & 13.0 & n.d. & n.d. & n.d. & n.d. & n.d. & n.d. & n.d. & \\
\hline NPN & 219.3 & 26,000 & $350 / 420$ & 36.5 & 7.0 & n.d. & n.d. & n.d. & n.d. & n.d. & n.d. & n.d. ! & \\
\hline DAPI & 277.3 & 27,000 & $358 / 461$ & 2.7 & 1.4 & n.d. & n.d. & n.d. & n.d. & n.d. & n.d. & n.d. i & \\
\hline ANS & 299.3 & 8,000 & $380 / 470$ & 15.1 & 6.2 & n.d. & n.d. & n.d. & n.d. & n.d. & n.d. & n.d. & \\
\hline Thioflavin T & 318.9 & 26,600 & $450 / 480$ & 27.5 & 20.6 & n.d. & n.d. & n.d. & n.d. & n.d. & n.d. & n.d. & \\
\hline
\end{tabular}

4 Next, we evaluated in-depth the spectral properties of 30 commonly available organic dyes 5 with our OICP tags. A representative characterization of OICP tags with Bodipy625 is 6 shown in Figure 2; the same characterization of 29 other dyes are shown in 7 Supplementary Figs. 2-18. With most dyes (except DFHBI), the fluorescence 8 enhancement, the enhanced absorbance, and lifetime increase are higher with RamR than 9 LmrR. The pertinent data are summarized in Table 1.

\footnotetext{
${ }^{1}$ DFHBI, 3,5-difluoro-4-hydroxybenzylidene imidazolinone; Probe 6, 10, 11, 15, 22 23, 29 and 33 are MaP probes developed by Prof. Kai Johnsson's laboratory(Wang et al., 2020). EtBr, ethidium bromide; DPH, 1,6-diphenyl-1,3,5hexatriene; NPN, 1-N-phenylnaphthylamine; DAPI, 4',6-diamidino-2-phenylindole; ANS, 8-Anilinonaphthalene-1-sulfonic acid (ANS); $F_{\text {RamR/LmrR }} / F_{0}$, Fold change in fluorescence of dye in presence of respective OICP tag compared to dye alone; $A_{\text {RamR/LmrR }} / A_{0}$, Fold change in absorbance of dye in presence of respective OICP tag compared to dye alone; $\mathrm{K}_{\mathrm{a}}$, association consants in $\mu \mathrm{M} ; \tau$, fluorescence lifetime of dye alone; $\tau_{\mathrm{RamR} / \mathrm{LmrR}}$, fluorescence lifetime of dye in presence of respective OICP tag. Data shown is an average of three independent measurements.
} 
a

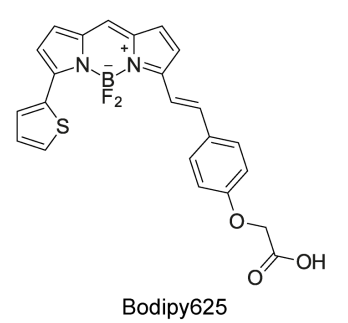

e

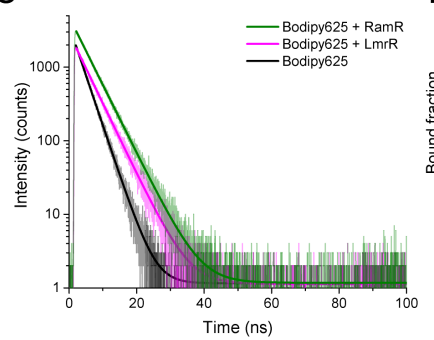

b

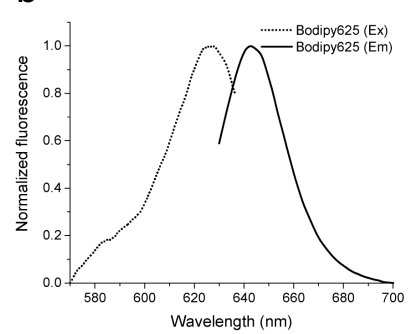

f
C

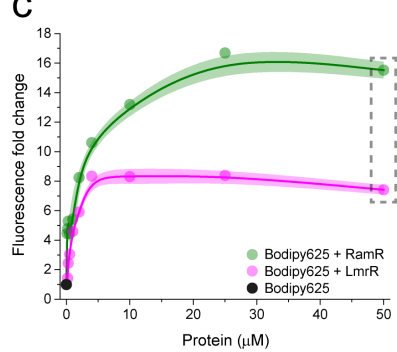

g

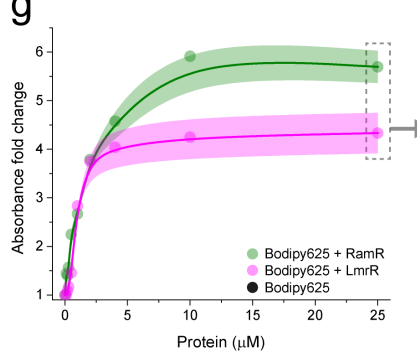

d

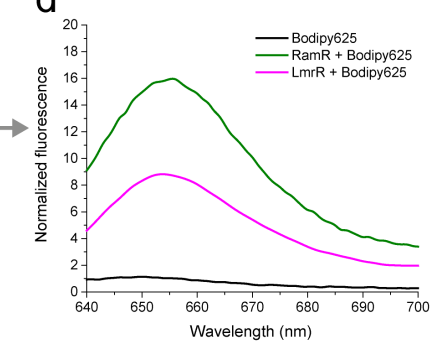

$\mathrm{h}$

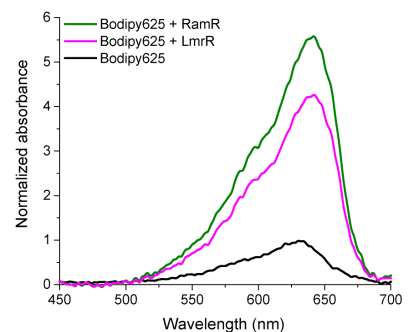

Figure 2. Representative characterization of OICP tags (RamR: green and LmrR: magenta) with Bodipy625. (a) Structure of Bodipy625. (b) Excitation (dotted line) and emission (solid line) spectra of Bodipy625. (c) Fluorescence fold change of Bodipy625 on titration with OICP tags. (d) Fluorescence emission spectra of Bodipy625 with OICP tags at a protein:dye molar ratio of 50:1. (e) Absorbance fold-change of Bodipy625 on titration with OICP tags. Solid lines represent spline fits and shaded regions represent s.d. over three independent measurements in panel (c) and (e). (f) Absorption spectra of Bodipy625 with OICP tags at a protein:dye molar ratio of 25:1. (g) Fluorescence lifetime spectra of Bodipy625 with OICP tags at a protein:dye molar ratio of 25:1 fit with a mono-exponential decay function (solid lines). (h) The bound fraction of Bodipy625 with OICP tags ascertained from a Hill fit. All experiments were performed at $30{ }^{\circ} \mathrm{C}$ in $20 \mathrm{mM} \mathrm{K}$ MOPS, $150 \mathrm{mM} \mathrm{NaCl}$ buffered at pH 7.0.

Overall, our in vitro characterization of 30 organic dyes demonstrates the applicability of our

tagging system in living cells. Our approach is easily extended to study the localization and dynamics of proteins in sub-compartments within living cells. To illustrate this, we tagged and labeled test proteins in the cytoplasm, inner membrane (penicillin-binding protein 5; PBP5), and periplasm (osmotically inducible protein Y; OsmY) of E. coli (Figure 3a). We chose Bodipy495 and Bodipy625 for these measurements since they show the highest fluorogenic behavior (Table 1), negligible background staining, and high cell permeabilities compared to other enhanced dyes (Supplementary Fig. 20-23). For cytoplasmic staining, we observe some non-specific binding of Bodipy495, likely to the inner membrane (Figure 3a: Cytoplasm), which is absent in controls (Supplementary Fig. 20). We confirmed specific targeting and labeling of the test proteins by performing fluorescence recovery after photobleaching measurements to compare the diffusion coefficients of test protein-OICP tag-dye conjugates with the same test proteins conjugated to a fluorescent protein, SuperFolder mTurquiose2ox(SfTq2) (Figure 3b). We find that the diffusion coefficients of the test proteins with dye conjugated-OICP and SfTq2 conjugated-OICP tags are comparable, with no indications for higher oligomer formation or protein aggregation. 
a

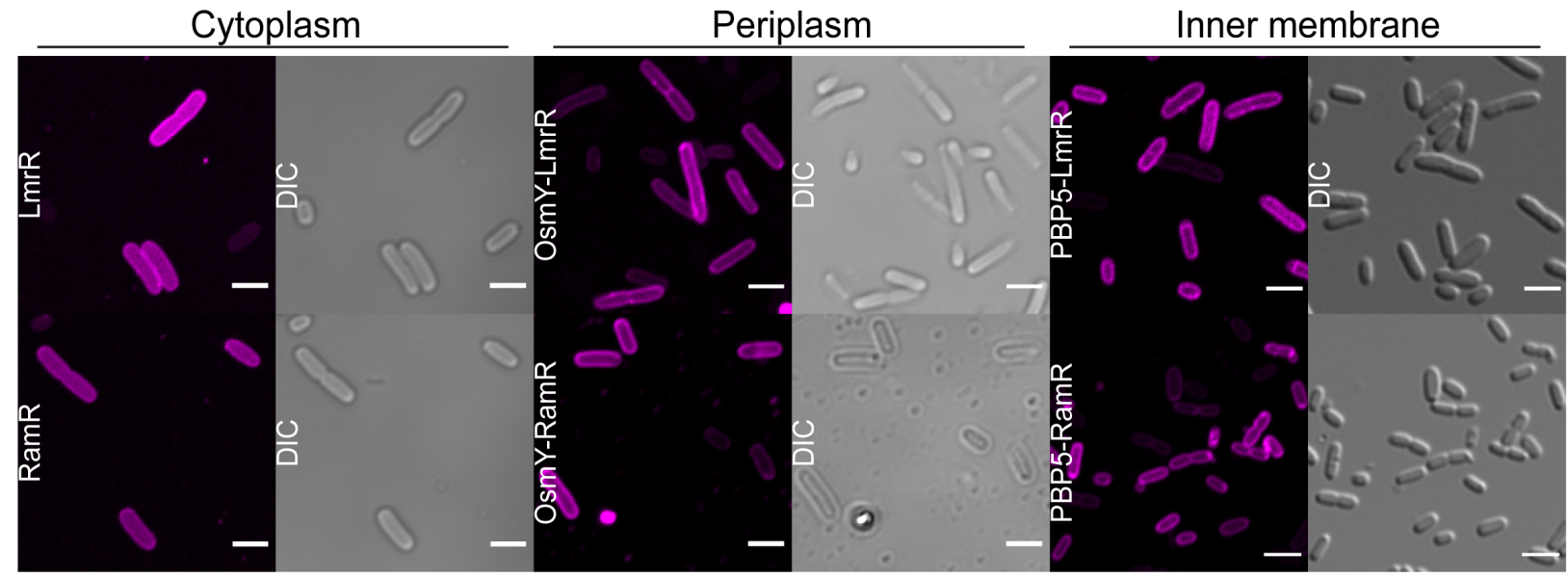

b

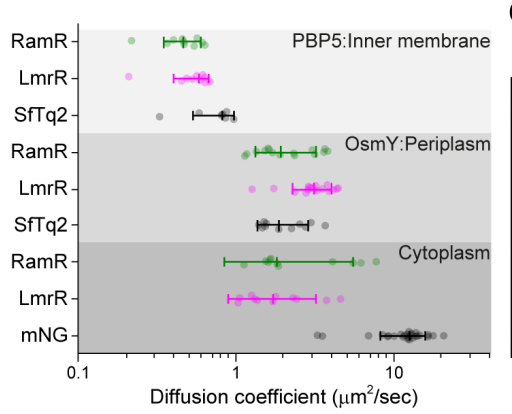

d

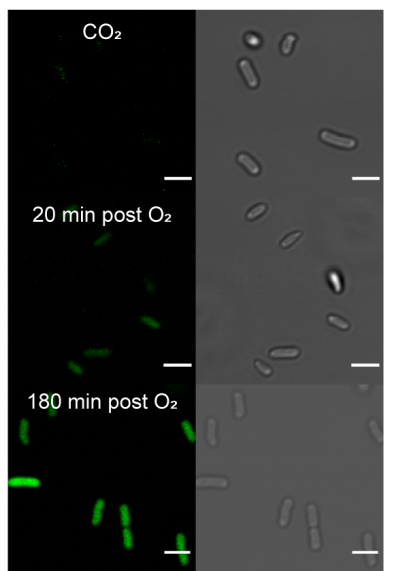

C

In vivo fluorescence $\left[-\mathrm{O}_{2}\right]$
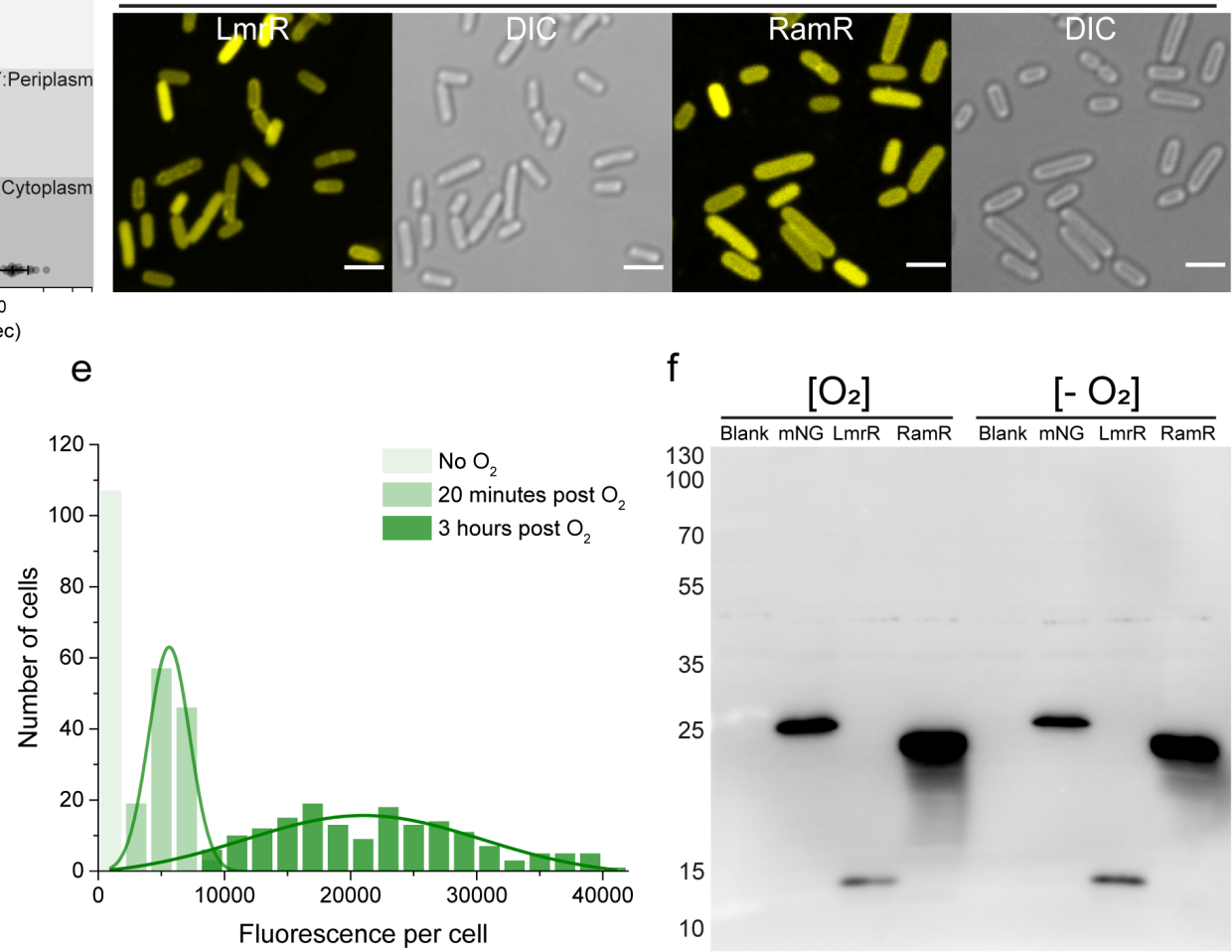

Figure 3. Compartmental labeling and oxygen-free imaging of OICP tags in E. coli. (a) Confocal and accompanying differential interference contrast (DIC) micrographs of live E. coli cells expressing OICP-tagged cytoplasmic ( $\mathrm{LmrR}$ or RamR only), periplasmic (OsmY) and inner membrane protein (PBP5) labeled with Bodipy495. (b) Diffusion coefficients of the aforementioned cytoplasmic, periplasmic, and inner membrane proteins compared with independent control proteins: fluorescent SuperFolder mTurquiose2ox(SfTq2) and mNeongreen (mNG) from FRAP measurements. (c-e) Confocal and accompanying differential interference contrast (DIC) micrographs of live E. coli cells expressing cytoplasmic OICP tags labeled with Bodipy625 under strictly anaerobic conditions (c), expressing cytoplasmic mNG protein (d); the integrated fluorescence histograms of the panel (d) are shown (e). (f) Western blots of OICP tags (15 and $23 \mathrm{kDa}$ for LmrR and RamR, respectively) and $\mathrm{mNG}$ protein $(26.6 \mathrm{kDa})$ expressed in the $E$. coli cytoplasm under aerobic and anaerobic conditions. Scale bars are $3 \mu \mathrm{m}$.

The oxygen-independent fluorescence enhancement in E. coli cultures expressing OICPtagged proteins under strictly anaerobic growth conditions (Figure 3c) and with purified OICP tags (Figure $1 \mathrm{~h}-\mathrm{i}$ ) remained comparable to that under aerobic conditions. The cell-tocell fluorescence intensity variation of Figure $3 a$ and $3 c$ is most likely due to differences in protein expression as we observe it with dye conjugated-OICP and SfTq2 conjugated-OICP 
1 tags. We benchmarked our OICP tags against the brightest available fluorescent protein:

2 mNeongreen (mNG)(Shaner et al., 2013). Under our experimental conditions, mNG

3 fluorescence was completely absent under anaerobic conditions, and the fluorescence

4 developed upon exposure of the cells to oxygen (Figure $3 \mathbf{d}-\mathbf{e}$ ). Both mNG and OICP tags

5 expressed well under aerobic or anaerobic conditions (Figure 3f). The expression of OICP

6 tags and their subsequent labeling with organic dyes do not affect the cell morphology of

7 exponentially growing E. coli, L. lactis, and S. cerevisiae cells (Supplementary Fig. 25).

8 We illustrate the usefulness of our labeling technology by targeting proteins with Bodipy625

9 in the cytoplasm of live Gram-negative (E. coli) and Gram-positive bacteria (L. lactis), and

10 the lower eukaryote Saccharomyces cerevisiae (Figure 4, and mitochondria of human

11 embryonic kidney (HEK) cells (Supplementary Figs. 24). We chose Bodipy625 since it

12 showed no detectable interactions with membranes and maximum permeability when

13 compared to the other six fluorogenic dyes (Supplementary Fig. 22-24) in E. coli, L. lactis,

14 and S. cerevisiae cells.

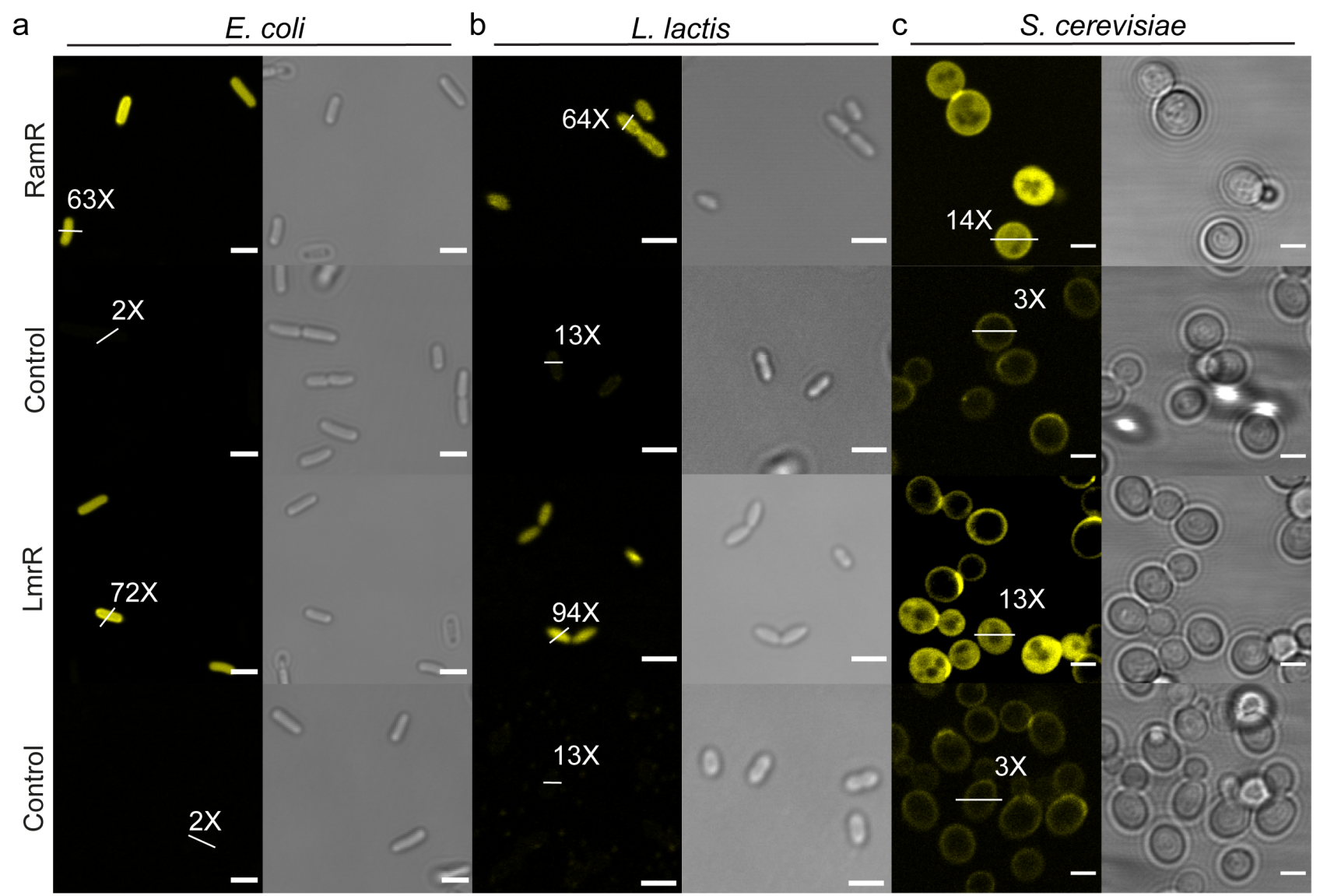

Figure 4. Live-cell imaging of OICP tags in prokaryotic and eukaryotic cells. (a) Fluorescence confocal and accompanying differential interference contrast (DIC) micrographs of E. coli, L. lactis and S. cerevisiae cytoplasm with Bodipy625 (yellow) from at least two independent biological replicates. White bars across arbitrarily picked cells depict signal to background fluorescence ratios. Scale bars: $3 \mu \mathrm{m}$. 
1 To estimate the fraction of labeled E. coli, L. lactis, and S. cerevisiae cells, we quantified

2 the fluorescence of live cells for the seven most useful dyes, using fluorescence flow-

3 cytometry (Supplementary Figs. 22-24). The fractions of labeled cells were highest with

4 Bodipy625 for E. coli (77\% for LmrR and $82 \%$ for RamR) and L. lactis (95\% for LmrR and

$591 \%$ for RamR). For S. cerevisiae and HEK cells, only Bodipy625 entered the cytoplasm

6 and we observe a good fraction of labeled S. cerevisiae cells (32\% for LmrR and $53 \%$ for

7 RamR). We note that the approach worked less well with S. cerevisiae than with bacteria

8 as only Bodipy625 permeates the cell envelope of yeast and binds OICP tags. Moreover, in

9 contrast to that in E. coli or L. lactis, significant background fluorescence was observed with

10 Bodipy625 in HEK cells. The higher background fluorescence of some dyes is most likely

11 due to non-specific binding to intracellular membranes and/or proteins. Additionally, we

12 observe that Bodipy625 tends to accumulate specifically in mitochondria even in non-

13 transfected cells(Supplementary Figs. 24b-c).

14 The OICP tags natively form high-affinity dimers, but we did not observe any fluorescent 15 punctate spots in live cells, and thus we have no indication that our tags cause protein 16 aggregation (Supplementary Figs. 20-21). Dynamic non-specific interactions with other 17 proteins and RNA/DNA cannot be ruled out completely, but so far we have no indications 18 that they pose a problem to the cell.

\section{DISCUSSION}

21 The promiscuity in binding planar organic dyes in OICP tags stems from their biological 22 function as transcriptional factors, proteins that bind drug-like molecules signaling the 23 transcription of drug-exporting proteins. We have analyzed 30 planar organic dyes and 24 observed an array of spectral effects after the binding of the dyes to the OICP tags. For 25 some of the dyes, a distinct redshift and increase in fluorescence emission intensity 26 (classified as enhanced in Table 1) is observed in the presence of both OICP tags, which 27 correlates with an accompanying increase in dye absorbance and fluorescence lifetime. 28 These fluorophores bind with moderate to high affinity to the OICP tags, accompanied by a 29 significant increase in fluorescence lifetimes, indicating their future applicability in 30 fluorescence lifetime imaging microscopy studies. In general, dyes that show enhanced 31 fluorescence, spectral enhancements are generally more pronounced with RamR than 32 LmrR except for DFHBI.

33 It is tempting to speculate that the aforementioned differences arise from the presence of a 34 single dye-binding pocket in LmrR (formed at the dimer interface) and two apparent dye- 
1 binding pockets in RamR (Fig. 1a). However, the fold-changes in fluorescence scale non-

2 linearly when comparing RamR and LmrR, which may be due to an excited-state cross-talk

3 between the two bound dye molecules in RamR. In dyes wherein the emission

4 fluorescence is either quenched or remain unaffected, the correlation between absorption,

5 fluorescence, and fluorescent lifetimes is not apparent. A peculiar case is Eosin $Y$, wherein

6 fluorescence lifetimes are equally enhanced in RamR and $L m r R$, but the fluorescence

7 emission intensity is quenched for $\mathrm{LmrR}$ and enhanced for RamR. Interactions of OICP

8 tags with AlexaFluor 488 were not detectable, suggesting little or no specificity for these

9 molecules. The structural promiscuity of the binding sites in both proteins allows capturing

10 of organic molecules not limited to this study, but also opens up possibilities of testing other

11 fluorophores with desired photochemical properties in our "plug-and-play" approach. For

12 instance, most of the MaP dyes(Wang et al., 2020) exhibit fluorogenicity with our OICP tags

13 (2-5 fold) and enhanced fluorescence lifetimes (20\%), circumventing the need for specific

14 chemistry between the tag and the ligand (Table 1 and Supplementary Fig. 18).

15 Although the promiscuity of the binding sites of the OICP tags enables the use of a wide 16 range of dyes, it also precludes us from delineating precisely the underlying processes 17 and/or interactions that contribute to the fluorogenicity and lifetime enhancements. The 18 selective interaction of OICP tags with the organic dyes arises likely from the geometry and 19 hydrophobicity of the binding pockets that are more accessible and/or hydrophobic than 20 other cellular structures. We observe fluorescence enhancements of intercalators with 21 OICP tags that are consistent with those typically observed in non-polar environments. The 22 stability of the interaction between OICP tags and organic dyes up to $800 \mathrm{mM} \mathrm{NaCl}$ further 23 suggests that OICP tags interact with the dyes predominantly through hydrophobic 24 contacts. Overall, the two OICP proteins impose a somewhat different (hydrophobic) 25 environment to the dyes, which could be exploited further by protein engineering. It should 26 be possible to design monomeric variants of RamR by mutating residues at the dimer 27 interface and decrease the size of the non-essential regions unimportant for fluorogenicity.

28 In addition to hydrophobic interactions, $\pi-\pi$ stacking involving aromatic residues (Phe-155 29 in RamR and Trp96 in LmrR) is critical for dye binding(Roelfes, 2019; Yamasaki et al., 2019, 30 2013). Indeed, the crystal structure of RamR with Rhodamine $6 G$ confirms the non-polar 31 nature of the binding pocket (Supplementary Fig. 26, panel a-b). The presence of 32 tryptophan, phenylalanine, and other hydrophobic amino acids in the binding pockets of 33 OICP tags results in multiple hydrophobic contacts and $\pi-\pi$ stacking interactions with the 34 electron-donating and/or electron-withdrawing groups of the organic dye. These 
1 interactions likely perturb the existing electron densities and concomitantly the excitation

2 and emission transition dipoles. The resulting properties are additionally influenced by

3 several factors, including changes in radiative and non-radiative decay rates (affecting

4 quantum yields), viscosity, dye conformational changes in the binding pocket not limited to 5 tautomeric changes, reduced rotational freedom due to steric hindrance or forced 6 planarization of out-of-plane twisted moieties influencing the HOMO-LUMO gap in the 7 organic dye. The overall net outcome of these interactions results in a specific spectral 8 signature for each dye-OICP pair. Importantly, the OICP tags are stable across a wide

9 range of physicochemical conditions, including $\mathrm{pH}$, temperature, ionic strength and oxygen, 10 and environments mimicking in vivo crowding (excluded volume effects); the latter has 11 been mimicked by using Ficoll70 as a synthetic macromolecular crowding agent. While the 12 affinity of binding of dyes to OICP tags is not affected by Ficoll70, the fluorogenicity is 13 decreased (Supplementary Fig. 19). By fine-tuning the chemical environment of the OICP 14 tags, specific photophysical properties of the interacting dyes can be exploited for in vivo 15 and in vitro applications.

16 In conclusion, we report the development and extensive characterization of two 17 chemogenetic protein tags that enable the use of organic fluorophores for live-cell imaging 18 and dynamic studies in bacterial, and lower eukaryotic cells and facilitate in vitro 19 applications under a wide range of conditions. The current inapplicability of our OICP tags 20 to mammalian cells calls for explorative studies with dyes not yet tested with our system 21 and shown to have low background signals or modification of existing dyes to reduce non22 specific background interactions inside the cells. Our method allows the use of cheap and 23 widely available organic fluorophores spanning the ultraviolet-visible-infrared spectrum, fast 24 and non-covalent labeling, and direct application in fluorescence lifetime imaging studies.

25 The stability of our OICP tags across a wide physiological range provides an imaging tool 26 for single-molecule studies into anaerobic gut microbes and other cells and organelles in 27 environments low in oxygen, and visualization and physiological studies of bacteria (and 28 their sub-compartments) living in extreme environments. We envision OICP tags to be 29 applicable in the burgeoning field of cellular cartography, in particular for (a) real-time 30 fluorescence monitoring for high-throughput screening of protein production and dynamics 31 in anaerobic gut microbes(Geva-Zatorsky et al., 2015) and extremophiles(Maslov et al., 32 2018); (b) real-time monitoring of protein stability and turnover(Ignatova and Gierasch, 33 2004); (c) acquisition of long single-molecule trajectories to characterize the diffusion of 34 proteins in the membranes; and (d) super-resolution imaging(Wang et al., 2019) and FLIM 35 studies of cells in a wide range of environments(Adhikari et al., 2019). 
bioRxiv preprint doi: https://doi.org/10.1101/2020.08.03.234815; this version posted August 4, 2020. The copyright holder for this preprint (which was not certified by peer review) is the author/funder. All rights reserved. No reuse allowed without permission. 


\section{METHODS}

\section{Construction of OICP tag plasmids}

\section{Escherichia coli}

4 The pET-17b plasmids encoding ImrR and ramR under an IPTG inducible T7 promoter 5 provided by Prof. Gerard Roelfes (University of Groningen) were used for protein expression and purification experiments. The DNA-binding capability of the LmrR was removed by substituting two lysine residues (K55 and K59) in the DNA-binding region of the protein by the negatively charged aspartic acid and neutral glutamine, respectively(Bos et al., 2013). The resulting $\mathrm{LmrR}(\mathrm{K} 55 \mathrm{D} / \mathrm{K} 59 \mathrm{Q})$ allowed easier purification of the protein and has reduced interactions with DNA. For facilitating studies in E. coli BW25113, the corresponding plasmids for $I m r R$ and ramR expression in the cytoplasm were created under the control of an arabinose-inducible promoter on a pBAD24 vector. Fusion constructs of ImrR and ramR with the periplasmic protein OsmY at the $\mathrm{N}$-terminus of the resulting fusion were created on a pBAD24 vector harboring an arabinose-inducible promoter. Fusion constructs of $I m r R$ and ramR with the inner membrane protein PBP5 (penicillin-binding protein 5) were created on the pNM077 vector harboring an IPTG-

17 inducible trc promoter provided by Prof. Tanneke Blaauwen (University of Amsterdam).

18 Amplification of $I m r R$ and ramR genes and corresponding plasmid backbones for USER

19 based cloning(Bitinaite et al., 2007) was performed using forward and reverse primers that 20 added a uracil residue instead of a thymine residue at flanking regions (see Appendix 2 for 21 primer sequences). The USER $®$ reaction for ligating fragments was performed as per 22 manufacturer's instructions(Bitinaite et al., 2007), followed by the heat-shock transformation 23 of chemically competent E. coli MC1061. Positive colonies were selected on LB- ampicillin $24(100 \mu \mathrm{g} / \mathrm{ml})$ plates and isolated plasmids were confirmed by DNA sequencing (Eurofins 25 Genomics Germany $\mathrm{GmbH}$ ). Thereafter the sequence-verified plasmids were transformed 26 into E. coli BW25113 and stored as glycerol stocks (30\% glycerol) until further use. The 27 DNA sequences for constructs are provided in Appendix 3.

\section{Lactococcus lactis}

29 All experiments were performed on the L. lactis strain NZ9000 $\Delta / m r R$ (Agustiandari et al., 30 2008). NZ9000 is a $L$. lactis MG1363 strain derivative containing the pepN::nisR/K(De 31 Ruyter et al., 1996) substitution, which in the presence of the inducer, nisin A, switches on 32 the expression of genes from the nisA promoter. By using the pNZ8048 vector housing the 33 nisA promoter, pNZ8048-ImrR was constructed(Agustiandari et al., 2008). The strain $34 \mathrm{NZ9000} \Delta / m r R$ (Agustiandari et al., 2008) lacks a chromosomal copy of the ImrR gene that 
served as a control for experiments with OICP tags. Both NZ9000 $\Delta / m r R$ (Agustiandari et al., 2008) strain and the plasmid pNZ8048-ImrR were provided by Prof. Arnold Driessen (University of Groningen). For the construction of nisin A-inducible plasmids for ramR, we cloned the native ramR gene into a pNZC3GH vector harboring a nisinA-inducible nisA promoter. However, we failed to observe any protein expression with this construct, which possibly arose because of codon-mismatch from the GC-rich native ramR sequence (Appendix 3). Next, we codon-optimized the ramR gene for L. lactis using the graphical codon usage analyzer tool(Fuhrmann et al., 2004) and synthesized the ramR gene

9 fragment(Geneart $\AA$, Regensburg, Germany). The amplification of the ramR gene and 10 corresponding plasmid pNZC3GH backbone for USER based cloning(Bitinaite et al., 2007) 11 was performed using forward and reverse primers that added a uracil residue instead of a 12 thymine residue at flanking regions. The resulting plasmid pNZC3GH-ramR was confirmed 13 by DNA sequencing (Eurofins Genomics Germany $\mathrm{GmbH}$ ) and transformed into the $L$. 14 lactis strain NZ9000 $\Delta / m r R$ (Agustiandari et al., 2008) by electroporation. The native and 15 codon-optimized DNA sequences for ramR are provided in Appendix 3.

\section{Saccharomyces cerevisiae}

17 We chose the cytoplasmic protein adenylosuccinate synthase (Ade12) for studies with our 18 OICP tags because of uniform cytoplasmic fluorescence(Munder et al., 2016). For plasmid 19 cloning, E. coli MC1061 was used for cloning and plasmid storage. The ade12 gene was 20 amplified using PCR from S. cerevisiae BY4742 chromosomal DNA using forward and 21 reverse primers that added a uracil residue instead of a thymine residue at flanking regions.

22 For plasmid backbone amplification, the multicopy plasmid pRSIl426 (housing the 23 selectable ura3 gene and allowing expression of a target protein from a constitutive ADH1 24 promoter) was used with forward and reverse primers that added a uracil residue instead of 25 a thymine residue at flanking regions. The USER $®$ reaction was performed as per manufacturer's instructions(Bitinaite et al., 2007) followed by the heat-shock transformation

27 of chemically competent E. coli MC1061. Positive colonies were selected on a LB 28 chloramphenicol $(32 \mu \mathrm{g} / \mathrm{ml})$ plates and isolated plasmids were confirmed by DNA 29 sequencing (Eurofins Genomics Germany $\mathrm{GmbH}$ ).

30 The correct plasmids were then transformed to $S$. cerevisiae strain BY4709 strains lacking 31 the ura3 gene enabling uracil based selection. Transformation of plasmids into $S$. 32 cerevisiae was performed as described elsewhere(Drew et al., 2008) with some minor 33 modifications. In short, single colonies were inoculated into $5 \mathrm{ml}$ yeast extract peptone 34 dextrose (YPD) media and incubated at $30^{\circ} \mathrm{C}, 200 \mathrm{rpm}$ overnight. The following day cells 
1 were diluted to $\mathrm{OD}_{600} \sim 0.1 \mathrm{in} 50 \mathrm{ml}$ of media and grown at $30{ }^{\circ} \mathrm{C}, 200 \mathrm{rpm}$ until a target

$2 \mathrm{OD}_{600} \sim 0.4-0.6$ was reached. Once the target $\mathrm{OD}_{600}$ was reached cells were pelleted, the

3 supernatant was removed and pellets resuspended in sterile $\mathrm{H}_{2} \mathrm{O}$ to wash. Cells were kept on ice throughout the transformation procedure. The wash step was repeated and then cells were resuspended in $1 \mathrm{ml} 0.1 \mathrm{M}$ lithium acetate. Cells were pelleted and resuspended in the required volume of $0.1 \mathrm{M}$ Lithium acetate before $50 \mu \mathrm{l}$ was added to (50 \%w/v) PEG4000 and samples were vortexed until homogenous. $25 \mu \mathrm{l}$ of $(2 \mathrm{mg} / \mathrm{ml})$ single-stranded salmon sperm was added to the cell suspension and vortexed again. Finally, $50 \mu l$ of corresponding plasmid DNA (250 ng - $1 \mu \mathrm{g}$ ) was added to the cell suspension before

10 vortexing and incubation at $30{ }^{\circ} \mathrm{C}$ with shaking for 30 minutes. Heat-shock was carried out 11 for 25 minutes at $42{ }^{\circ} \mathrm{C}$ with shaking before cells were pelleted, resuspended in $200 \mu$ of 12 sterile $\mathrm{H}_{2} \mathrm{O}$, and plated onto uracil lacking agar plates. After plates were incubated at $30{ }^{\circ} \mathrm{C}$ 13 for 48 - 72 hours single colonies were selected for re-streaking on selective agar plates to 14 attain a monoclonal population. Single colonies from the monoclonal population were then 15 selected for confirmation of positive clones by plasmid isolation and subsequent 16 sequencing of the coding region (Eurofins Genomics Germany $\mathrm{GmbH}$ ).

\section{HEK-293T cells}

18 pmTurquoise2-Mito was a gift from Dorus Gadella(Goedhart et al., 2012) (Addgene plasmid 19 \# 36208). Cox8A-RmrR-FLAG is a fusion construct comprising of 29 amino acids of 20 COX8A (a mitochondrial targeting signal), RamR codon-optimized for mammalian 21 expression and a FLAG-tag. Expression was in pcDNA3.1 from the constitutive CMV 22 (human cytomegalovirus) promotor. The complete sequence of the RamR construct used is 23 given in Appendix 3.

\section{Protein expression and purification}

Chemically competent BL21(DE3) E. coli cells were transformed with a pET17b expression vectors carrying cyto-LmrR and cyto-RamR constructs under the control of a T7 RNA polymerase promoter $(p(T 7))$. Single colonies were picked and inoculated into a starter culture of $10 \mathrm{ml}$ of fresh lysogeny broth (LB) medium (10 g/l tryptone, $5 \mathrm{~g} / \mathrm{l}$ yeast extract, 30 and $10 \mathrm{~g} / \mathrm{l} \mathrm{NaCl}$ ) containing $100 \mu \mathrm{g} / \mathrm{mL}$ of ampicillin and grown at $37^{\circ} \mathrm{C}$ with $180 \mathrm{rpm}$ 31 shaking overnight. The following day, the saturated LB culture was diluted 100-fold in a 500 $32 \mathrm{ml}$ fresh LB medium in a 2 I Erlenmeyer flask containing $100 \mu \mathrm{g} / \mathrm{ml}$ of ampicillin and allowed

33 to grow at $37{ }^{\circ} \mathrm{C}$ with $180 \mathrm{rpm}$ shaking until the culture reached an $\mathrm{OD}_{600}$ of $0.84-0.90$. At 34 this stage, isopropyl $\beta$-D-1-thiogalactopyranoside (IPTG) at a final concentration of $1 \mathrm{mM}$ 
1 was added to induce the expression of the target protein and expressions were carried out

2 at $30{ }^{\circ} \mathrm{C}$ with $180 \mathrm{rpm}$ shaking overnight. The next day, cells were harvested by 3 centrifugation (6000 rpm, JA10, $20 \mathrm{~min}, 4{ }^{\circ} \mathrm{C}$, Beckman). The pellet was re-suspended in $15-20 \mathrm{ml}$ of $50 \mathrm{mM} \mathrm{NaH}_{2} \mathrm{PO}_{4}, \mathrm{pH} 8.0,150 \mathrm{mM} \mathrm{NaCl}$ with half a tablet of mini complete EDTA-free protease inhibitor cocktail (Roche) and $1 \mathrm{mM}$ of the serine protease inhibitor Phenylmethanesulfonyl fluoride (PMSF). Next, Dnasel (final concentration, $0.1 \mathrm{mg} / \mathrm{mL}$ ) and $\mathrm{MgCl}_{2}$ (final concentration, $10 \mathrm{mM}$ ) were added. Sonication was carried out (tip diameter $6 \mathrm{~mm}, 75 \%(200 \mathrm{~W})$ for $8 \mathrm{~min}$ (10 s on, $15 \mathrm{~s}$ off). Additional sheer forcing with a syringe and

9 a long needle was applied for at least 2 times. Henceforth, all steps were carried out at 4 ${ }^{\circ} \mathrm{C}$.

11 The cell lysates obtained after sonication were centrifuged (16000 rpm, JA-17, 45 min, 4

$12{ }^{\circ} \mathrm{C}$, Beckman) to remove unlysed cells and other high molecular weight debris. The cell-free 13 extract was then filtered and equilibrated with $5 \mathrm{ml}$ of pre-equilibrated Strep-Tactin $®$ column 14 material for $1 \mathrm{~h}$ (mixed at $200 \mathrm{rpm}$ on a rotary shaker). The column was washed with $3 \times 2$ $15 \mathrm{CV}$ (column volume) of re-suspension buffer (same as buffer used before) and eluted 16 multiple times with $0.5 \mathrm{CV}$ (6-7 times) of elution buffer (resuspension buffer containing 5 $17 \mathrm{mM}$ desthiobiotin). Fractions were analyzed on a $12 \%$ polyacrylamide SDS-Tris Tricine gel 18 followed by Coomassie Blue staining. Fractions containing protein (excluding the first 19 elution) were concentrated in centrifugal filters and re-buffered to $20 \mathrm{mM} \mathrm{K}-\mathrm{MOPS}, \mathrm{pH} 7.0$, $20150 \mathrm{mM} \mathrm{NaCl}$ using dialysis (reduces DNA contamination in elution fractions). The 21 concentration of purified LmrR and RamR was determined by using the calculated 22 extinction coefficient obtained from Protparam on the Expasy server ( $\varepsilon_{280}$ for $\mathrm{LmrR}$ 23 monomer $=25,440 \mathrm{M}^{-1} \mathrm{~cm}^{-1}$ and that of RamR monomer $=29,450 \mathrm{M}^{-1} \mathrm{~cm}^{-1}$ ). Expression 24 yields typically were $30-40 \mathrm{mg} / \mathrm{l}$ for $\mathrm{LmrR}$ and $40-50 \mathrm{mg} / \mathrm{l}$ for RamR. Aliquots of $500 \mu \mathrm{l}$ were 25 flash-freezed using liquid nitrogen until use. Thawed protein samples for analysis were not 26 frozen a second time and used within 24 hours.

27 For purification of HisTag containing proteins, a $\mathrm{Ni}^{2+}$-Sepharose resin was used. The resin 28 was pre-equilibrated in $50 \mathrm{mM} \mathrm{KPi}, 150 \mathrm{mM} \mathrm{NaCl}, \mathrm{pH}$ 7.0, with $10 \mathrm{mM}$ imidazole. The cell29 free extract was added to the $\mathrm{Ni2}+-$ Sepharose resin $(0.5 \mathrm{ml}$ bed volume per $10 \mathrm{mg}$ total 30 protein) and nutated for $3 \mathrm{~h}$ after which the resin was washed with 20 column volumes of $3150 \mathrm{mM} \mathrm{KPi}, 150 \mathrm{mM} \mathrm{NaCl}, \mathrm{pH} 7.0$, with $50 \mathrm{mM}$ imidazole. Proteins were then eluted with $3250 \mathrm{mM} \mathrm{KPi}, 150 \mathrm{mM} \mathrm{NaCl}, \mathrm{pH} 7.0$, with $500 \mathrm{mM}$ imidazole in $500 \mu$ l aliquots. The most 33 concentrated fractions were run on a Superdex15 Increase 10/300 GL size-exclusion 34 column (GE Healthcare) in $20 \mathrm{mM} \mathrm{K-MOPS,} \mathrm{pH} 7.0$ with $150 \mathrm{mM} \mathrm{NaCl}$. Protein containing 35 fractions were pooled and concentrated to $5 \mathrm{mg} / \mathrm{ml}$ in a Vivaspin $500(3 \mathrm{kDa})$ centrifugal 
1 concentrator (Sartorius AG), after which they were aliquoted, flash-frozen in $500 \mu$ aliquots

2 and stored at $-80^{\circ} \mathrm{C}$.

\section{Absorption and fluorescence spectroscopy}

4 Organic dyes were prepared as stock solutions $(2.5-5 \mathrm{mM})$ in DMSO and diluted for spectroscopy to a final concentration of $1 \mu \mathrm{M}$ in $20 \mathrm{mM} \mathrm{K}-\mathrm{MOPS}, 150 \mathrm{mM} \mathrm{NaCl}, \mathrm{pH} 7.0$ such that the DMSO concentration did not exceed $0.5 \%(\mathrm{v} / \mathrm{v})$. Purified RamR and $\mathrm{LmrR}$ were then added and incubated for less than a 1 minute before the measurement of absorption and fluorescence spectra. All measurements (3 independent replicates) were

9 taken at $30{ }^{\circ} \mathrm{C}$. Samples were incubated for 1-2 minutes after mixing gently with a pipette 10 and thereafter measured in black polystyrene, $\mu$ Clear® bottom, 96-well plates (Greiner Bio11 One, cat. 655096) and for samples having excitation wavelength $<400 \mathrm{~nm}$ on 96-well 12 plates with a UV-compatible optical bottom (Greiner Bio-One, cat. 655801) on a TECAN 13 Spark $® 10 \mathrm{M}$ microplate reader. Reported values are averages of 3 independent 14 experiments. The obtained results are concisely summarized in Table 1 in the main text 15 and an extended version of the table with details of organic dyes and error bars for each 16 measurement are summarized in Supplementary Table 1. Experiments to determine 17 bound fraction was performed for each dye by keeping the dye concentration constant to 18 avoid any inner filter effects due to increasing dye concentrations. By keeping the dye 19 concentration constant at $1 \mu \mathrm{M}$, protein concentrations were increased until the 20 fluorescence emission intensity saturated resulting in an apparent binding curve. The 21 association constant $\mathrm{K}_{\mathrm{a}}$ was then estimated by fitting the data points to a Hill model. The 22 same samples were also used for absorption spectroscopy to validate if the spectral 23 changes observed in fluorescence emission emanated from changes in absorption.

24 Fluorescence emission and absorption spectra of the organic dyes in presence of OICP 25 tags were normalized against that of the organic dyes alone giving a fold-change (from peak values) in absorption and fluorescence emission(panel c and e in Supplementary

27 Figs. 2-18). At saturation values of OICP tags with the organic dyes, a normalized 28 fluorescence emission spectra and absorption spectra are depicted in panel $d$ and $f$ in

29 Supplementary Figs. 2-18. The excitation and emission bandwidths were set to $5 \mathrm{~nm}$ for 30 all measurements.

31 For $\mathrm{pH}, \mathrm{NaCl}$ and temperature scans, purified RamR and $\mathrm{LmrR}$ were used at a final 32 concentration of $4 \mu \mathrm{M}$ and $50 \mu \mathrm{M}$, respectively, in $20 \mathrm{mM} \mathrm{MOPS}, 150 \mathrm{mM} \mathrm{NaCl}, \mathrm{pH} 7.0$ 33 with Bodipy495. The buffer $\mathrm{pH}$ was adjusted using $\mathrm{KOH}$ (K-MOPS). Buffer exchange for $\mathrm{pH}$ 34 scan measurements was performed using Thermo Scientific ${ }^{\text {TM }}$ Zeba $^{\text {TM }}$ Spin desalting 
1 columns and the $\mathrm{pH}$ was verified subsequently using a $\mathrm{pH}$ meter. For $\mathrm{pH}$ values in the

2 range 4-7, a citric acid- $\mathrm{Na}_{2} \mathrm{HPO}_{4}$ buffer was used supplemented with $150 \mathrm{mM} \mathrm{NaCl}$. For $\mathrm{pH}$

3 values between $\mathrm{pH}$ values 6.5 and $8,50 \mathrm{mM}$ sodium phosphate buffers supplemented with

$4150 \mathrm{mM} \mathrm{NaCl}$ were used at $30^{\circ} \mathrm{C}$ keeping the dye and OICP tag concentration constant.

5 To probe the stability of our OICP tags with increasing ionic strengths, we modulated the

6 concentration of $\mathrm{NaCl}$ in $20 \mathrm{mM} \mathrm{K-MOPS,} 150 \mathrm{mM} \mathrm{NaCl}, \mathrm{pH} 7.0$ buffer keeping the dye,

7 and OICP tag concentration constant. The color-shaded regions represent the standard

8 deviation (s.d.) over three independent measurements.

9 Temperature scan measurements were performed in Teflon sealed quartz cuvettes in an

10 FP-8300 spectrofluorimeter (Jasco, Inc.) equipped with a temperature modulation system

11 (Julabo $\mathrm{GmbH}$ ). The temperature rise gradient was $1{ }^{\circ} \mathrm{C} / \mathrm{min}$ and an additional minute was

12 allowed to equilibrate samples at a given temperature. Samples were excited at $480 \mathrm{~nm}$

13 and the emission spectra were acquired from 495 to $600 \mathrm{~nm}$ with $1 \mathrm{~nm}$ data interval and 5

$14{ }^{\circ} \mathrm{C}$ temperature intervals from $20{ }^{\circ} \mathrm{C}$ to $60{ }^{\circ} \mathrm{C}$. Excitation and emission bandwidths were 15 kept constant at $5 \mathrm{~nm}$. Reported values are averages of independent experiments. For 16 temperature scan, beyond $55{ }^{\circ} \mathrm{C}$, visible white precipitates could be observed for OICP 17 tags indicated with a dotted line in Fig. 1f.

18 For measurements under strictly anaerobic conditions, $20 \mathrm{mM} \mathrm{K-MOPS,} 150 \mathrm{mM} \mathrm{NaCl}$ 19 buffered at $\mathrm{pH} 7.0$ was prepared and equilibrated in the $\mathrm{CO}_{2}$ hood at least for a week 20 before measurements.

\section{Fluorescence lifetime}

22 The fluorescence lifetime measurements were acquired at a $10 \mathrm{MHz}$ repetition rate for 30 23 seconds on a MicroTime 200 confocal microscope (PicoQuant, Berlin, Germany) on glass24 bottom dishes (Willco Wells ${ }^{\circledR}$, cat. HBST-3522). Purified RamR and LmrR were used at a 25 final concentration of $4 \mu \mathrm{M}$ and $50 \mu \mathrm{M}$ respectively in $20 \mathrm{mM} \mathrm{K}-\mathrm{MOPS}, 150 \mathrm{mM} \mathrm{NaCl}, \mathrm{pH}$ 267.0 with $1 \mu \mathrm{M}$ of organic dye. The exponential-tail fitting of the lifetime decay was done with 27 the SymphoTime software. Reported values are averages of independent experiments and 28 the accompanying error bars represent s.d. at ambient temperature $\left(\sim 25^{\circ} \mathrm{C}\right)$. The laser 29 excitation modules employed in the MicroTime 200 confocal microscope were $440 \mathrm{~nm}, 485$ $30 \mathrm{~nm}, 532 \mathrm{~nm}, 595 \mathrm{~nm}$, and $640 \mathrm{~nm}$. 
1 Fluorescence confocal microscopy and phase contrast microscopy

Preparation of glass slides

3 To ensure the immobility of $E$. coli cells we used (3-aminopropyl)triethoxysilane (APTES)treated glass cover slides. The glass slides were first cleaned by sonicating them for $1 \mathrm{hr}$ in $5 \mathrm{M} \mathrm{KOH}$, followed by rinsing at least 10 times with MilliQ and blowing off the remaining MilliQ with pressurized nitrogen. Next, the glass slides were immersed in acetone containing $2 \%$ v/v APTES for 30 minutes at room temperature. Thereafter we removed the acetone and APTES and rinsed the slides 10 times with MilliQ. Again, the remaining MilliQ

9 was blown off with pressurized nitrogen. The glass slides were used within 2 days of 10 preparation. The cells were concentrated to an $\mathrm{OD}_{600} \sim 1$ and after adding $20 \mu \mathrm{l}$ cells on 11 the APTES slide, a clean object slide was put on the top and the whole assembly was put 12 up inverted in the microscope stage.

13 For L. lactis cells, the glass slides were first cleaned by sonicating them for $1 \mathrm{hr}$ in $5 \mathrm{M}$ $14 \mathrm{KOH}$, followed by rinsing at least 10 times with MilliQ and blowing off the remaining MilliQ 15 with pressurized nitrogen. The glass slides were used within 2 days of preparation. The 16 cells were concentrated to an $\mathrm{OD}_{600} \sim 1$ and after adding $20 \mu \mathrm{l}$ cells on the cleaned slide, a 17 clean object slide was put on the top and the whole assembly was put up inverted in the 18 microscope stage.

19 For S. cerevisiae cells, a similar glass slide cleaning protocol as aforementioned for $L$. 20 lactis cells was followed and the cleaned slides were used in a stick-Slide 8 well chamber 21 (Ibidi $\mathrm{GmbH}$, cat. 80828). The cells were concentrated to an $\mathrm{OD}_{600} \sim 0.5$ and $100 \mu \mathrm{l}$ cells 22 were added in each chamber.

23 Preparation of E. coli for fluorescence confocal microscopy and phase contrast 24 microscopy

25 For each experiment, a glycerol stock of $E$. coli BW25113 with desired LmrR/RamR variant 26 on a pBAD plasmid was stabbed with a sterile pipette tip and deposited in 3 ml lysogeny 27 broth (LB Lennox: $10 \mathrm{~g} / \mathrm{l}$ tryptone, $5 \mathrm{~g} / \mathrm{l}$ yeast extract, $5 \mathrm{~g} / \mathrm{l} \mathrm{NaCl}$ ) containing $0.2 \% \mathrm{v} / \mathrm{v}$ 28 glycerol and $100 \mu \mathrm{g} / \mathrm{mL}$ ampicillin. The LB medium was then incubated at $37^{\circ} \mathrm{C}$ with 200 29 rpm shaking. The next day, the saturated LB culture was diluted 100 -fold in a $3 \mathrm{ml}$ fresh LB 30 medium containing $0.2 \% \mathrm{v} / \mathrm{v}$ glycerol and $100 \mu \mathrm{g} / \mathrm{ml}$ ampicillin. The LB medium was then 31 incubated at $37{ }^{\circ} \mathrm{C}$ with $200 \mathrm{rpm}$ shaking until the culture reached an $\mathrm{OD}_{600}$ of $0.7-0.8$. At 32 this stage, protein expression was induced using $0.1 \% \mathrm{w} / \mathrm{v}$ arabinose, and the cultures 33 were then incubated at $30{ }^{\circ} \mathrm{C}$ with $200 \mathrm{rpm}$ shaking overnight. The following day, the 34 saturated LB culture was diluted 100 -fold in a $3 \mathrm{ml}$ fresh LB medium containing $0.2 \% \mathrm{v} / \mathrm{v}$ 
1 glycerol, $0.1 \%$ arabinose, $100 \mu \mathrm{g} / \mathrm{ml}$ ampicillin and allowed to grow until the culture reached

2 an $\mathrm{OD}_{600}$ of $0.4-0.6$. These cells were now directly used for labeling and consecutive

3 imaging. For dye labeling, $0.5 \mathrm{ml}$ of $\mathrm{OD}_{600}$ of 0.6 cultures were centrifuged at $11000 \mathrm{~g}$ for 1

4 minute and a final concentration of $15 \mu \mathrm{M}$ dye was added. The pellet was gently

5 resuspended and the cell suspension was kept at $30{ }^{\circ} \mathrm{C}$ for 30 minutes. Thereafter, the

6 suspension was centrifuged at $11000 \mathrm{~g}$ for 1 minute and the cell pellet was washed 3 times

7 with $1 \mathrm{ml}$ of LB medium. The washing step was repeated 3 times to ensure the removal of

8 free dye. The resulting suspension was now used for confocal fluorescence microscopy

9 and phase-contrast microscopy.

Preparation of $L$. lactis for fluorescence confocal microscopy and phase contrast microscopy

13 For experiments with LmrR, a glycerol stock of Lactococcus lactis NZ9000 $\Delta / m r R$ cells with

14 desired LmrR/RamR variant on a nisin-inducible plasmid was stabbed with a sterile pipette

15 tip to obtain a small number of cells. Lactococcus lactis NZ9000 was grown in M17 medium

16 (Difco, Franklin Lakes, NJ, USA) supplemented with 1\% (w/v) glucose (GM17) and $5 \mu \mathrm{g} / \mathrm{ml}$

17 chloramphenicol at $30^{\circ} \mathrm{C}$ without shaking. We incubated the cultures at $30{ }^{\circ} \mathrm{C}$, without

18 shaking since $L$. lactis is facultatively anaerobic. The next day, the saturated culture was

19 diluted 100X in a fresh $3 \mathrm{ml} \mathrm{GM} 17$ medium containing $5 \mu \mathrm{g} / \mathrm{ml}$ chloramphenicol and

20 incubated at $30{ }^{\circ} \mathrm{C}$ without shaking until $\mathrm{OD}_{600}$ reached 0.3 . At this stage, we added $2 \mu$ of

21 nisinA solution (filtered supernatant from a L. lactis NZ9700 culture), and the culture was

22 allowed to grow overnight at $30^{\circ} \mathrm{C}$ without shaking. On the morning of the next day, about

$23100 \mu \mathrm{l}$ of culture was added to $4 \mathrm{ml}$ of fresh GM17 medium containing $5 \mu \mathrm{g} / \mathrm{ml}$

24 chloramphenicol and $2 \mu \mathrm{l}$ nisinA solution, to yield an $\mathrm{OD}_{600} \sim 0.1$. The cultures were then

25 incubated at $30^{\circ} \mathrm{C}$ until $O D_{600}$ reached 0.4 . These cells were now directly used for labeling 26 and consecutive imaging. For dye labeling, $0.5 \mathrm{ml}$ of $O D_{600}$ of 0.6 cultures were centrifuged

27 at $11000 \mathrm{~g}$ for 1 minute and a final concentration of $15 \mu \mathrm{M}$ dye was added. The pellet was 28 gently resuspended and the cell suspension was kept at $30{ }^{\circ} \mathrm{C}$ for 30 minutes. Thereafter, 29 the suspension was centrifuged at $11000 \mathrm{~g}$ for 1 minute and the cell pellet was washed 3 30 times with $1 \mathrm{ml}$ of LB medium. The washing step was repeated 3 times to ensure the 31 removal of free dye. The resulting suspension was now used for confocal fluorescence 32 microscopy and phase-contrast microscopy. 
1 Preparation of S. cerevisiae for fluorescence confocal microscopy, phase contrast

2 microscopy, and flow cytometry experiments

3 S. cerevisiae was grown in a minimal synthetic defined (SD) media including a yeast 4 nitrogen base lacking riboflavin and folic acid, ammonium sulfate, and $2 \%$ glucose as a 5 carbon source. Riboflavin was not added to prevent interactions with OICP tags. For each 6 experiment, single colonies from uracil lacking synthetic defined (SD URA-) plates were 7 inoculated into $5 \mathrm{ml}$ SD URA- media and incubated at $30^{\circ} \mathrm{C}, 200 \mathrm{rpm}$ overnight. The 8 following day cells were diluted to $\mathrm{OD}_{600} \sim 0.02$ in $5 \mathrm{ml}$ of media and grown at $30{ }^{\circ} \mathrm{C}, 200$ 9 rpm, and maintained in exponential phase for three consecutive days. On the day of the 10 experiment, once the $O D_{600}$ reached 0.5 , cells were pelleted at $8000 \mathrm{~g}$ for 1 minute in $1.5 \mathrm{ml}$ 11 sterile Eppendorf tubes, the supernatant was removed and pellets resuspended in sterile 12 SD URA- media to a final $O D_{600}$ of 1 . These cells were now directly used for labeling and 13 consecutive imaging. For dye labeling, $0.5 \mathrm{ml}$ of $\mathrm{OD}_{600}$ of 0.6 cultures were centrifuged at $1411000 \mathrm{~g}$ for 1 minute and a final concentration of $15 \mu \mathrm{M}$ dye was added. The pellet was 15 gently resuspended and the cell suspension was kept at $30{ }^{\circ} \mathrm{C}$ for 30 minutes. Thereafter, 16 the suspension was centrifuged at $11000 \mathrm{~g}$ for 1 minute and the cell pellet was washed 3 17 times with $1 \mathrm{ml}$ of LB medium. The washing step was repeated 3 times to ensure the 18 removal of free dye. The resulting suspension was now used for confocal fluorescence 19 microscopy and phase-contrast microscopy.

\section{Preparation of mammalian cells (HEK293T) for transfection and fluorescence confocal microscopy}

100,000 HEK293T cells were cultured in a $35 \mathrm{~mm}$ imaging dish with a glass bottom and an 24 imprinted $50 \mu \mathrm{m}$ cell location grid (Ibidi; Cat.No:81148) in DMEM medium supplemented with $1 \%(\mathrm{v} / \mathrm{v})$ Na-pyruvate, $1 \%(\mathrm{v} / \mathrm{v})$ antibiotics, $1 \%(\mathrm{v} / \mathrm{v})$ glutamine and $10 \%(\mathrm{v} / \mathrm{v})$ fetal calf serum (FCS). JetPEI (PolyPlus; Cat.No: 101-10N) was used to co-transfect cells with pmTurquoise2-Mito and Cox8-RamR-FLAG constructs. $16 \mathrm{hr}$ post-transfection, the cells were washed with phenol-red free, serum-free, antibiotic-free RPMI imaging medium (ThermoFisher; Cat.No: 11835030) containing 1\% glutamine. Bodipy625 was diluted in the 30 imaging medium to a final concentration of $450 \mathrm{nM}$. After $15 \mathrm{~min}$ of incubation at $37^{\circ} \mathrm{C}$, the 31 free dye was washed away with the imaging medium. Cells were imaged live at $37^{\circ} \mathrm{C}$ by confocal imaging and their positions on the grid were marked. Subsequently, the cells then were washed with PBS, fixed with 4\% paraformaldehyde (PAF) for 15 min, and permeabilized with $0.1 \%$ Triton-X100 in PBS for 5 min. Cells were immunolabeled with mouse IgG1 Anti-Flag antibody (Sigma; Cat. No: F1804) over-night at dilution 1:200 in 
antibody conjugated to Alexa Fluor 568 (ThermoFisher; Cat.No: A10037) at dilution 1:400 in PBS for 30 min. Finally, cells located at the stored positions on the grid were imaged by

3 confocal microscopy.

4

\section{Imaging}

Confocal laser scanning microscopy (LSM 710, Carl Zeiss AG Jena, Germany) equipped with a C-Apochromat 40x/1.2 NA objective was used for in vivo fluorescence imaging of live E. coli, L. lactis, S. cerevisiae cells. $405 \mathrm{~nm}, 488 \mathrm{~nm} 543 \mathrm{~nm}$ and $632 \mathrm{~nm}$ lasers were employed for fluorescence excitation. For all measurements, data were acquired within 20 minutes and thereafter a fresh slide was used. The stage temperature was maintained at $30^{\circ} \mathrm{C}$. We recorded 16-bit images at randomized positions on the glass slide with $512 \times 512$ pixels $(34.19 \mu \mathrm{m} \times 34.19 \mu \mathrm{m})$ and analyzed at least 100 cells for each dye with a corresponding OICP tag. All images were collected under identical conditions of power and gain for a given dye. For anaerobic fluorescence imaging, experiments were performed in a sterile glove box maintained constantly under a $5 \% \mathrm{CO}_{2}$ environment. Control experiments to verify oxygen unavailability were performed by assessing $\mathrm{mNG}$ fluorescence in $E$. coli BW25113 housing a pBAD-mNG plasmid in a TECAN multi-well plate reader inside the glove box. To avoid any recovery of the fluorescent protein mNeonGreen (mNG) fluorescence during cell harvesting, all steps until slide preparation were done in the sterile glove box. The same samples when exposed to air gained fluorescence with saturated over time. For anaerobic imaging, cytoplasmic LmrR and RamR proteins were expressed from a pBAD24 plasmid under conditions identical to those performed in presence of oxygen.

Phase-contrast images were acquired using an Axio Observer Z1 microscope (Carl Zeiss, Jena, Germany) equipped with a C-Apochromat 100x/1.49 NA objective for imaging of live E. coli, L. lactis, S. cerevisiae cells. For all measurements, data were acquired within 20 minutes and thereafter a fresh slide was used. The stage temperature was maintained at $30^{\circ} \mathrm{C}$. We recorded 16 -bit images at randomized positions on the glass slide with $1024 \mathrm{x}$ 1024 pixels $(66.05 \mu \mathrm{m} \times 66.05 \mu \mathrm{m})$ and analyzed at least 100 cells for each dye with a corresponding OICP tag. Cell aspect ratios (length/width) were obtained using the MicrobeJ plugin in Fiji. Fiji(Schindelin et al., 2012) was used for all image analysis of confocal and phase-contrast microscopy images.

For imaging HEK cells, a confocal laser scanning microscope (LSM800, Carl Zeiss AG Jena, Germany) equipped with a $63 \mathrm{X}$ oil immersion objective was used. A $640 \mathrm{~nm}$ laser was employed for Bodipy625 excitation. The stage temperature was maintained at $30^{\circ} \mathrm{C}$. All images were collected under identical conditions of power and gain for a given dye. 
1 Fluorescence Recovery After Photobleaching (FRAP)

2 We performed fluorescence recovery after photo-bleaching (FRAP; see Figure 1a,b) on an

3 LSM710 Zeiss confocal laser scanning microscope (Zeiss, Oberkochen, Germany) as

4 reported previously by our group(Mika et al., 2014; Schavemaker et al., 2017), based on a

5 previously described method(Elowitz et al., 1999). We programmed the microscope to take

6 three images (pre-bleach), then photobleached the cell at one of the poles, and finally

7 record the recovery of the fluorescence over time. We ensured that we picked cells lying

8 flat on one position without exhibiting any rotational or translational motion during the time

9 of measurement, not undergoing cell division, and having no neighbors that would obscure

10 the analysis.

\section{Flow cytometry}

12 Live cells were prepared and labeled identically as for confocal fluorescence microscopy.

13 For E. coli, L. lactis and S. cerevisiae cells, firstly using the FSC/SSC gating, cell debris

14 was removed from the main cell population. A positivity threshold gate for each sample was

15 defined based on unlabeled $(0 \%)$ and labeled control cells expressing no protein $(<3 \%)$.

16 An identical positivity threshold gate was applied to all samples for a given organic dye.

17 Samples were measured on an LSR-II flow cytometer (BD Bioscience) with 10000 events

18 for each sample and analyzed with Kaluza Analysis 2.1 software (Beckman Coulter, CA,

19 USA). The data was acquired (18 bits digitalization in 5 decades) using DIVA 8.0 software

20 and saved as FCS 3.0 or 3.1 files. The following laser and corresponding filter sets (dye:

21 laser; peak/bandwidth) were employed: a) DHFBI: 405; 525/15,b) Bodipy488 and

22 Bodipy495: 488; 530/30, c) Rhodamine 6G and Rose Bengal: 561; 585/15, d) Bodipy589:

23 561; 615/20 and e) Bodipy625: 635; 660/30). At least two independent biological replicate

24 measurements were performed for each sample. For DFHBI, the excitation laser and the

25 fluorescence filter sets are not ideal, which may result in an underestimation of the fraction

26 of labeled cells. The gating strategy is given in Appendix 4. For HEK293T cells, a starting

27 cell population per sample was collected with the stopping rule of 30,000 events per

28 preliminary gate drawn in FSC/SSC in a CytoFlex LX (Beckman Coulter) flow cytometer.

29 Next, the cells were analyzed placing gates on PE (phycoerythrin) channel indicating

30 FLAG expression labeled with Alexa Fluor 568. APC (allophycocyanin) filter was used to 31 detect Bodipy-625 fluorescence. Negative/high background populations were defined by 32 unstained cells visible in the PE channel and un-transfected but Bodipy-625 pulsed cells in

33 APC channel. All experimental data were analyzed in Kaluza Analysis 2.1 software. 
1 Size-Exclusion Chromatography with Multiangle Laser Light Scattering (SEC-

2 MALLS) detection

3 The column was equilibrated with $20 \mathrm{mM} \mathrm{K-MOPS,} 150 \mathrm{mM} \mathrm{NaCl}(\mathrm{pH}$ 7.0). The Superdex

4200 column used for the SEC-MALLS analysis was equilibrated with $20 \mathrm{mM} \mathrm{K-MOPS,} 150$

$5 \mathrm{mM} \mathrm{NaCl}$ buffered at $\mathrm{pH}$ 7.0, filtered through $0.1 \mu \mathrm{m}$ pore size VVLP filters (Millipore)) and

6 subsequently the buffer was recirculated through the system for $16 \mathrm{~h}$ at $0.5 \mathrm{ml} / \mathrm{min}$. This

7 allowed the buffer to pass several times through the degasser and the pre-injection filter,

8 thereby thoroughly removing air and particles and allowed a judgement of the stability of

9 detector baselines. $400 \mu \mathrm{l}$ of protein solution $(0.4 \mathrm{mg} / \mathrm{ml})$ was injected and the data from the

10 three detectors were imported by the ASTRA software package version 5.3.2.10 (Wyatt

11 Technologies). For instrument calibration and analysis, aldolase protein was used as an

12 internal standard.

\section{Gel electrophoresis and Western blot}

14 E. coli cells expressing cytoplasmic LmrR, RamR and mNG tagged with a C-terminal 6-

15 HisTag were initially centrifuged at $11000 \mathrm{~g}$ to remove spent media and the cell pellet was 16 resuspended in $50 \mathrm{mM} \mathrm{KPi}, 100 \mathrm{mM} \mathrm{NaCl}$ (PBS) buffered at pH 7.0 to a final $\mathrm{OD}_{600}$ of 6 . 17 Samples were thereafter loaded with $5 \mathrm{X}$ SDS loading buffer, heated at $90^{\circ} \mathrm{C}$ for 5 minutes, 18 and were separated using a 15\% SDS-polyacrylamide gel. Proteins were blotted onto 19 polyvinylidene difluoride (PVDF) membranes for 35 minutes at a constant current of $0.08 \mathrm{~A}$.

20 Blots were blocked for 2 hours in freshly prepared $0.2 \%(w / v) ~ I-b l o c k \circledast$ in $0.2 \%$ 21 (w/v)Tween20 containing $50 \mathrm{mM} \mathrm{KPi}, 100 \mathrm{mM} \mathrm{NaCl}$ (PBST) buffered at pH 7.0. HRP22 conjugated anti-HisTag antibodies were incubated for 1 hour at 1:6000 dilution in PBST 23 buffer and washed 3 times for $5 \mathrm{~min}$ in $0.2 \%(\mathrm{w} / \mathrm{v})$ l-block® in PBST buffer, followed by 24 washing 3 times for 5 minutes in PBS buffer. For the chemiluminescent readout, the Super 25 Signal West Pico (Thermo Scientific) substrate was used according to the manufacturer's 26 instructions. Chemiluminescent detection was performed on a LAS-4000 mini (Fujifilm, 27 Düsseldorf, Germany). 


\section{ACKNOWLEDGMENTS}

2 We thank our colleagues in the Membrane Enzymology group at the University of

3 Groningen for their valuable suggestions; Dr. Jonas Cremer (University of

4 Groningen/Stanford University) who helped with the cultivation and analysis of cells under

5 strictly anaerobic conditions; Prof. Tanneke Blaauwen (University of Amsterdam) who

6 kindly provided the fluorescent SuperFolder mTurquoise (sfTq2) and PBP5-sfTq2

7 constructs; Geert Mesander of the University Medical Center Groningen for assistance in

8 fluorescence-activated cell sorting measurements; Dr. Viktor Krasnikov for assistance in

9 fluorescence lifetime measurements; Prof. Kai Johnsson for providing the MaP dyes; Dr.

10 Arnold Driessen (University of Groningen) for kindly providing the pNSC8048 plasmid

11 (carrying the ImrR gene) and L. lactis ImrR knockout strain, and Michele Partipilo for

12 providing the pNZC $3 G \mathrm{G}$ plasmid. This research was funded by an ERC Advanced grant

13 (ABCVolume; \#670578).

\section{AUTHOR INFORMATION}

\section{Corresponding Authors}

17 *Aditya lyer - Department of Biochemistry, Groningen Biomolecular Sciences and

18 Biotechnology Institute, University of Groningen, Nijenborgh 7, 9747 AG Groningen, The

19 Netherlands; orcid.org/0000-0002-3144-6385

20 *Bert Poolman - Department of Biochemistry, Groningen Biomolecular Sciences and

21 Biotechnology Institute, University of Groningen, Nijenborgh 7, 9747 AG Groningen, The

22 Netherlands; orcid/org/0000-0002-1455-531X

\section{AUTHOR CONTRIBUTIONS}

25 A.I., S.C., G.R., GvdB, and B.P. conceived the project and designed the experiments. A.I. 26 and S.C. designed and performed cloning experiments in E. coli, L. lactis and S. cerevisiae 27 and purified OICP tags. A.I. performed most of the bacterial cloning, microscopy 28 experiments, and analyzed the data. A.I. and A.J.F. designed and performed cloning and 29 microscopy experiments in S. cerevisiae. M.B. designed and performed experiments in 30 mammalian cells. A.I. and B.P. wrote the paper. 


\section{ADDITIONAL FILES}

2 The complete in vitro and in vivo characterization of 30 organic dyes with OICP tags, 3 representative images of labeled E. coli, L. lactis, S. cerevisiae, and HEK cells with 7

4 fluorogenic dyes, the effect of Ficoll70 on fluorogenicity, the gating strategy for flow

5 cytometry and accompanying data with the fraction of labeled cells, the effect of dye

6 labeling on cell morphology, the strains, and plasmids used in the study, is available in

7 supporting information.

\section{COMPETING INTERESTS}

9 The authors declare no competing financial interests.

\section{ABBREVIATIONS}

11 BODIPY, 4,4-difluoro-4-bora-3a,4a-diaza-s-indacene; s.d., standard deviation; HOMO, 12 highest occupied molecular orbital; LUMO, lowest unoccupied molecular orbital 
1. Adhikari S, Moscatelli J, Smith EM, Banerjee C, Puchner EM. 2019. Single-molecule localization microscopy and tracking with red-shifted states of conventional BODIPY conjugates in living cells. Nat Commun 10.

2. Agustiandari $H$, Lubelski J, Van Den Berg Van Saparoea HB, Kuipers OP, Driessen AJM. 2008. LmrR is a transcriptional repressor of expression of the multidrug $A B C$ transporter LmrCD in Lactococcus lactis. J Bacteriol 190:759-763.

3. Balleza E, Kim JM, Cluzel P. 2018. Systematic characterization of maturation time of fluorescent proteins in living cells. Nat Methods 15:47-51.

4. Bitinaite J, Rubino M, Varma KH, Schildkraut I, Vaisvila R, Vaiskunaite R. 2007. USER $^{\mathrm{TM}}$ friendly DNA engineering and cloning method by uracil excision. Nucleic Acids Res 35:1992-2002.

5. Bos J, García-Herraiz A, Roelfes G. 2013. An enantioselective artificial metallohydratase. Chem Sci 4:3578-3582.

6. Bosch PJ, Corrêa IR, Sonntag MH, Ibach J, Brunsveld L, Kanger JS, Subramaniam V. 2014. Evaluation of fluorophores to label SNAP-Tag fused proteins for multicolor singlemolecule tracking microscopy in live cells. Biophys $J$ 107:803-814.

7. Cranfill PJ, Sell BR, Baird MA, Allen JR, Lavagnino Z, De Gruiter HM, Kremers GJ, Davidson MW, Ustione A, Piston DW. 2016. Quantitative assessment of fluorescent proteins. Nat Methods 13:557-562.

8. De Ruyter PGGA, Kuipers OP, De Vos WM. 1996. Controlled gene expression systems for Lactococcus lactis with the food- grade inducer nisin. Appl Environ Microbiol 62:3662-3667.

9. Dippel AB, Anderson WA, Park JH, Yildiz FH, Hammond MC. 2020. Development of Ratiometric Bioluminescent Sensors for in Vivo Detection of Bacterial Signaling. ACS Chem Biol 15:904-914.

10.Drepper T, Eggert T, Circolone F, Heck A, Krauß U, Guterl JK, Wendorff M, Losi A, Gärtner W, Jaeger KE. 2007. Reporter proteins for in vivo fluorescence without oxygen. Nat Biotechnol 25:443-445.

11. Drew D, Newstead S, Sonoda Y, Kim H, von Heijne G, Iwata S. 2008. GFP-based optimization scheme for the overexpression and purification of eukaryotic membrane proteins in Saccharomyces cerevisiae. Nat Protoc 3:784-798.

12. Elowitz MB, Surette MG, Wolf PE, Stock JB, Leibler S. 1999. Protein mobility in the cytoplasm of Escherichia coli. J Bacteriol 181:197-203.

13. Fuhrmann M, Hausherr A, Ferbitz L, Schödl T, Heitzer M, Hegemann P. 2004. Monitoring dynamic expression of nuclear genes in Chlamydomonas reinhardtii by using a synthetic luciferase reporter gene. Plant Mol Biol 55:869-881.

14. Geva-Zatorsky N, Alvarez D, Hudak JE, Reading NC, Erturk-Hasdemir D, Dasgupta S, von Andrian UH, Kasper DL. 2015. In vivo imaging and tracking of host-microbiota interactions via metabolic labeling of gut anaerobic bacteria. Nat Med 21:1091-1100.

15. Goedhart J, Von Stetten D, Noirclerc-Savoye M, Lelimousin M, Joosen L, Hink MA, Van Weeren L, Gadella TWJ, Royant A. 2012. Structure-guided evolution of cyan fluorescent proteins towards a quantum yield of $93 \%$. Nat Commun 3 .

16. Grimm JB, English BP, Choi H, Muthusamy AK, Mehl BP, Dong P, Brown TA, Lippincott-Schwartz J, Liu Z, Lionnet T, Lavis LD. 2016. Bright photoactivatable fluorophores for single-molecule imaging. Nat Methods 13:985-988.

17. Grimm JB, Muthusamy AK, Liang Y, Brown TA, Lemon WC, Patel R, Lu R, Macklin JJ, Keller PJ, Ji N, Lavis LD. 2017. A general method to fine-tune fluorophores for live-cell and in vivo imaging. Nat Methods 14:987-994.

18. Ignatova Z, Gierasch LM. 2004. Monitoring protein stability and aggregation in vivo by real-time fluorescent labeling. Proc Natl Acad Sci U S A 101:523-528. 
19. Jing C, Cornish VW. 2011. Chemical tags for labeling proteins inside living cells. AcC Chem Res 44:784-792.

20. Keppler A, Pick H, Arrivoli C, Vogel H, Johnsson K. 2004. Labeling of fusion proteins with synthetic fluorophores in live cells. Proc Natl Acad Sci U S A 101:9955-9959.

21. Kocaoglu O, Carlson EE. 2016. Progress and prospects for small-molecule probes of bacterial imaging. Nat Chem Biol 12:472-478.

22. Kowada T, Maeda H, Kikuchi K. 2015. BODIPY-based probes for the fluorescence imaging of biomolecules in living cells. Chem Soc Rev 44:4953-4972.

23. Kumagai A, Ando R, Miyatake H, Greimel P, Kobayashi T, Hirabayashi Y, Shimogori T, Miyawaki A. 2013. A bilirubin-inducible fluorescent protein from eel muscle. Cell 153:1602-1611.

24. Madoori PK, Agustiandari H, Driessen AJM, Thunnissen AMWH. 2009. Structure of the transcriptional regulator $\mathrm{LmrR}$ and its mechanism of multidrug recognition. $E M B O \mathrm{~J}$.

25. Maslov I, Bogorodskiy A, Mishin A, Okhrimenko I, Gushchin I, Kalenov S, Dencher NA, Fahlke C, Büldt G, Gordeliy V, Gensch T, Borshchevskiy V. 2018. Efficient noncytotoxic fluorescent staining of halophiles. Sci Rep 8.

26. Mejías SH, Roelfes G, Browne WR. 2020. Impact of binding to the multidrug resistance regulator protein LmrR on the photo-physics and -chemistry of photosensitizers. Phys Chem Chem Phys 22:12228-12238.

27. Mika JT, Schavemaker PE, Krasnikov V, Poolman B. 2014. Impact of osmotic stress on protein diffusion in Lactococcus lactis. Mol Microbio/ 94:857-870.

28. Munder MC, Midtvedt D, Franzmann T, Nüske E, Otto O, Herbig M, Ulbricht E, Müller $P$, Taubenberger A, Maharana S, Malinovska L, Richter D, Guck J, Zaburdaev V, Alberti S. 2016. A pH-driven transition of the cytoplasm from a fluid- to a solid-like state promotes entry into dormancy. Elife $\mathbf{5}$.

29. Nagai T, Ibata K, Park ES, Kubota M, Mikoshiba K, Miyawaki A. 2002. A variant of yellow fluorescent protein with fast and efficient maturation for cell-biological applications. Nat Biotechnol 20:87-90. doi:10.1038/nbt0102-87

30. Rodriguez EA, Campbell RE, Lin JY, Lin MZ, Miyawaki A, Palmer AE, Shu X, Zhang J, Tsien RY. 2016. The Growing and Glowing Toolbox of Fluorescent and Photoactive Proteins. Trends Biochem Sci 13:1-19.

31. Roelfes G. 2019. LmrR: A Privileged Scaffold for Artificial Metalloenzymes. Acc Chem Res 52:545-556.

32. Schavemaker PE, Śmigiel WM, Poolman B. 2017. Ribosome surface properties may impose limits on the nature of the cytoplasmic proteome. Elife 6.

33. Schindelin J, Arganda-Carreras I, Frise E, Kaynig V, Longair M, Pietzsch T, Preibisch S, Rueden C, Saalfeld S, Schmid B, Tinevez JY, White DJ, Hartenstein V, Eliceiri K, Tomancak P, Cardona A. 2012. Fiji: An open-source platform for biological-image analysis. Nat Methods 9:676-682.

34. Shaner NC, Lambert GG, Chammas A, Ni Y, Cranfill PJ, Baird MA, Sell BR, Allen JR, Day RN, Israelsson M, Davidson MW, Wang J. 2013. A bright monomeric green fluorescent protein derived from Branchiostoma lanceolatum. Nat Methods 10:407-409.

35. Shaner NC, Steinbach PA, Tsien RY. 2005. A guide to choosing fluorescent proteins. Nat Methods 2:905-909.

36. Song W, Strack RL, Svensen N, Jaffrey SR. 2014. Plug-and-play fluorophores extend the spectral properties of spinach. J Am Chem Soc 136:1198-1201.

37. Takeuchi K, Tokunaga Y, Imai M, Takahashi H, Shimada I. 2014. Dynamic multidrug recognition by multidrug transcriptional repressor LmrR. Sci Rep 4:1-12.

38. Tropini C, Earle KA, Huang KC, Sonnenburg JL. 2017. The Gut Microbiome: Connecting Spatial Organization to Function. Cell Host Microbe 21:433-442.

39. Tsien RY. 1998. The green fluorescent protein. Annu Rev Biochem 67:509-544.

40. Wang L, Frei MS, Salim A, Johnsson K. 2019. Small-Molecule Fluorescent Probes for Live-Cell Super-Resolution Microscopy. J Am Chem Soc 141:2770-2781. 
41.Wang L, Tran M, D'Este E, Roberti J, Koch B, Xue L, Johnsson K. 2020. A general strategy to develop cell permeable and fluorogenic probes for multicolour nanoscopy. Nat Chem 12:165-172.

42. Yamasaki S, Nakashima R, Sakurai K, Baucheron S, Giraud E, Doublet B, Cloeckaert A, Nishino K. 2019. Crystal structure of the multidrug resistance regulator RamR complexed with bile acids. Sci Rep 9.

43. Yamasaki S, Nikaido E, Nakashima R, Sakurai K, Fujiwara D, Fujii I, Nishino K. 2013. The crystal structure of multidrug-resistance regulator RamR with multiple drugs. Nat Commun 4:2078. 